\title{
Progressive Transneuronal Changes in the Brainstem and Thalamus after Long-Term Dorsal Rhizotomies in Adult Macaque Monkeys
}

\author{
Timothy M. Woods, ${ }^{1}$ Catherine G. Cusick, ${ }^{2}$ Tim P. Pons, ${ }^{3}$ Edward Taub, ${ }^{4}$ and Edward G. Jones ${ }^{1}$ \\ ${ }^{1}$ Center for Neuroscience, University of California, Davis, California 95616, 2Department of Structural and Cellular Biology, \\ Tulane University Medical Center, New Orleans, Louisiana 70112, 32Department of Neurosurgery, Wake Forest University \\ School of Medicine, Winston-Salem, North Carolina 27157, and ${ }^{4}$ Department of Psychology, University of Alabama at \\ Birmingham, Birmingham, Alabama 35294
}

This study deals with a potential brainstem and thalamic substrate for the extensive reorganization of somatosensory cortical maps that occurs after chronic, large-scale loss of peripheral input. Transneuronal atrophy occurred in neurons of the dorsal column (DCN) and ventral posterior lateral thalamic (VPL) nuclei in monkeys subjected to cervical and upper thoracic dorsal rhizotomies for 13-21 years and that had shown extensive representational plasticity in somatosensory cortex and thalamus in other experiments. Volumes of DCN and VPL, number and sizes of neurons, and neuronal packing density were measured by unbiased stereological techniques. When compared with the opposite, unaffected, side, the ipsilateral cuneate nucleus $(\mathrm{CN})$, external cuneate nucleus (ECN), and contralateral VPL showed reductions in volume: $44-51 \%$ in CN, $37-48 \%$ in ECN, and $32-38 \%$ in VPL. In the affected nuclei, neurons were progressively shrunken with increasing survival

Loss of peripheral sensory input is associated with reorganization of representational maps in adult primate somatosensory cortex (SI) (Kaas et al., 1983; Merzenich et al., 1983, 1984; Kaas, 1995). This reorganization may underlie perturbed sensory experiences occurring after peripheral deafferentation or amputation of a limb in humans (Flor et al., 1995; Knecht et al., 1996; Elbert et al., 1997). Extensive reorganization of cortical maps in adult monkeys was demonstrated after long-term survivals following massive peripheral deafferentation. Dorsal rhizotomies from the second cervical (C2) to fourth thoracic (T4) roots, after a survival of 13-15 years, were associated with an expansion of the cortical representation of the lower face into the silenced upper limb representation, a distance of $10-14 \mathrm{~mm}$, bringing the representation of the face immediately adjacent to the representation of the (lower) trunk (Pons et al., 1991). Similar effects occurred 6-12 months after transection of the cuneate fasciculus at cervical levels (Jain et al., 1997) or after long-term amputation of a hand (Florence and Kaas, 1995).

Until recently, explanations offered to account for this degree

Received Jan. 18, 2000; revised Feb. 23, 2000; accepted Feb. 28, 2000.

This work was supported by Grants NS21377 (E. G. J.), NS35246 and MH53369 (T. P. P.), and EY08906 (C. G. C.) from the National Institutes of Health, US Public Health Service. We thank Dr. G. Popken, P. L. Nguyen, and C. Ho for technical assistance and Drs. R. Blanchard, P. J. Gerone, M. Mishkin, M. Ratteree, and W. Raub for helping make the work possible.

Correspondence should be addressed to Dr. Edward G. Jones, Center for Neuroscience, 1544 Newton Court, Davis, CA 95616. E-mail: ejones@ucdavis.edu.

Copyright (C) 2000 Society for Neuroscience $0270-6474 / 00 / 203884-16 \$ 15.00 / 0$ time, and their packing density increased, but there was relatively little loss of neurons (10-16\%). There was evidence for loss of axons of atrophic CN cells in the medial lemniscus and in the thalamus, with accompanying severe disorganization of the parts of the ventral posterior nuclei representing the normally innervated face and the deafferented upper limb. Secondary transneuronal atrophy in VPL, associated with retraction of axons of $\mathrm{CN}$ neurons undergoing primary transneuronal atrophy, is likely to be associated with similar withdrawal of axons from the cerebral cortex and should be a powerful influence on reorganization of somatotopic maps in the somatosensory cortex.

Key words: plasticity; dorsal rhizotomy; transneuronal atrophy; dorsal column nuclei; ventral posterior lateral nucleus; stereology

of cortical reorganization focused on intracortical mechanisms and included unmasking of preexisting and highly divergent thalamocortical connections (Rausell and Jones, 1995; Jones et al., 1997; Rausell et al., 1998) or of long-range intracortical connections (De Felipe et al., 1986; Burton and Fabri, 1995; Manger et al., 1997) and/or sprouting of intracortical or thalamocortical axons (Darian-Smith and Gilbert, 1994; Florence and Kaas, 1995; Florence et al., 1998). Older evidence for activitydependent reorganization of the dorsal column and ventral posterior thalamic nuclei, which, if projected onto the cortex, would have considerable influence on the body map in SI, tended to be underestimated (for review, see Jones, 2000). Recent studies show that representational plasticity akin to that found in the cortex does occur at these lower levels of the somatosensory system in both the short and long term (Lenz et al., 1994; Jones and Pons, 1998a,b; Xu and Wall, 1999a). However, the morphological basis for these changes remains unexplored.

Transneuronal atrophy occurring as a primary response to loss of afferents in the dorsal column nuclei and as a secondary phenomenon in the thalamus has recently been suggested as a stimulus to representational plasticity in the cortex, because withdrawal of axons of atrophying cells could induce plastic changes in intact afferents (Jones and Pons, 1998a,b). In the same monkeys that showed massive expansion of the cortical lower face representation after chronic C2-T4 dorsal rhizotomies (Pons et al., 1991), the cuneate and ventral posterior lateral (VPL) nuclei had become affected by severe transneuronal atrophy, with ex- 
Table 1. Number of neurons in dorsal column nuclei of monkeys after chronic dorsal rhizotomies

\begin{tabular}{|c|c|c|c|c|c|c|c|}
\hline \multirow[b]{2}{*}{ Case } & \multirow[b]{2}{*}{ Survival time (years) } & \multicolumn{2}{|l|}{$\mathrm{CN}$} & \multicolumn{2}{|l|}{$\mathrm{ECN}$} & \multicolumn{2}{|l|}{ GN } \\
\hline & & Intact & Deafferented & Intact & Deafferented & Intact & Deafferented \\
\hline 1 & 12.8 & $140,578.45$ & $127,299.81$ & $53,823.21$ & $49,530.15$ & $56,145.53$ & $58,037.23$ \\
\hline 2 & 13.7 & $119,005.20$ & $111,331.60$ & $64,264.60$ & $55,211.89$ & $76,532.21$ & $78,031.44$ \\
\hline 3 & 13.7 & $142,320.60$ & $129,819.10$ & $66,012.90$ & $59,756.42$ & $91,094.53$ & $90,041.99$ \\
\hline 4 & 14.3 & $143,658.53$ & $129,483.38$ & $61,458.56$ & $56,438.48$ & $73,568.51$ & $72,986.95$ \\
\hline 5 & 15.1 & $130,453.30$ & $114,025.80$ & $55,401.74$ & $54,033.80$ & $79,968.00$ & $81,195.56$ \\
\hline 6 & 15.1 & $160,869.51$ & $144,099.09$ & $66,341.29$ & $61,825.31$ & $82,517.68$ & $79,876.31$ \\
\hline 7 & 21.2 & $115,782.47$ & $98,058.30$ & $64,985.12$ & $53,947.63$ & $94,036.18$ & $94,758.32$ \\
\hline Mean & & $136,095.44$ & $122,016.73$ & $61,755.34$ & $55,820.53$ & $79,123.23$ & $79,275.40$ \\
\hline $\mathrm{SD}$ & & $15,632.93$ & $15,188.81$ & $5,152.03$ & $4,053.11$ & $2,539.85$ & $11,915.26$ \\
\hline
\end{tabular}

pansion of the lower face representation in the disorganized thalamus (Jones and Pons, 1998a,b). This expansion may have been of sufficient extent to account for expansion of the lower face representation in the cortex. The present study characterizes and quantifies the extent of transneuronal atrophy in brainstem and thalamus in these chronically deafferented monkeys, using unbiased stereological techniques.

Preliminary results have been published previously (Rausell et al., 1992; Jones and Pons, 1998a,b; Woods et al., 1998, 1999).

\section{MATERIALS AND METHODS}

Dorsal rhizotomies. The dorsal roots of the spinal cord from the $\mathrm{C} 2$ through the T4 segment were transected unilaterally in seven and bilaterally in one young adult Macaca fascicularis monkeys (Taub, 1980). Body weights of the animals were between 2.8 and $5.1 \mathrm{~kg}$ at the time of surgery. Survival times ranged from 12.8 to 21.2 years (Table 1). Defects reported during the survival period included neglect of the affected limb, shortening of the affected limb, wrist deformities, and cervical spinal fusion. Several monkeys showed repeated, self-inflicted injuries of the affected limb that in two cases were sufficiently severe to require therapeutic amputation (cases 1 and 7 of the present series).

In four of the monkeys, $12.8,13.7$, or 14.3 years after deafferentation, electrophysiological mapping was performed on the first somatic sensory area (SI) of the cerebral cortex contralateral to the rhizotomies (cases 1-4 of the present series) (Pons et al., 1991), and in two of the monkeys, the contralateral VPL was mapped after 15.1 or 21.2 years of deafferentation (cases 5 and 7 of the present series) (Jones and Pons, 1998a,b). The remaining two monkeys, including the one deafferented bilaterally, were not subjected to physiological experimentation.

Histological processing. The animals were given an overdose of sodium pentobarbital and perfused through the heart with $500 \mathrm{ml}$ of normal saline followed by 31 of $4 \%$ paraformaldehyde, $4 \%$ paraformaldehyde, and $0.5 \%$ glutaraldehyde, or $2 \%$ paraformaldehyde and $0.2 \%$ glutaraldehyde in $0.1 \mathrm{~m}$ phosphate buffer, $\mathrm{pH}$ 7.2. The brains were removed, blocked, post-fixed overnight in 2 or $4 \%$ paraformaldehyde, infiltrated with $30 \%$ sucrose, and frozen in dry ice. Blocks of brainstem and thalamus were cut into serial $25-\mu \mathrm{m}$-thick sections on a freezing microtome, and alternate sections were stained with thionin, for cytochrome oxidase $(\mathrm{CO})$, or immunocytochemically for the calcium-binding proteins calbindin-D28K and parvalbumin or for various other antigens (Rausell et al., 1992). Six additional brains, from normal M. fascicularis monkeys, were fixed, sectioned, and stained by identical methods to serve as controls for the staining patterns in the brainstem and thalamus.

Stereology. For measurements of the dorsal column nuclei (DCN), quantification was performed on all seven of the monkeys that received unilateral dorsal rhizotomies; for measurements of the ventral posterior nucleus (VPL) of the thalamus, three of the seven with unilateral rhizotomies were used. For the DCN measurements, survival times were 12.8, 13.7 (two cases), 14.3-15.1 (three cases), and 21.2 years after rhizotomy; for the VPL measurements, survival times were 12.8, 13.7, and 21.2 years after rhizotomy (Tables 1-4). The volumes of the DCN and VPL and the numbers and sizes of the neurons within them were measured using unbiased stereological techniques. Neuronal packing densities were calculated from these figures. Counts and measurements were performed on thionin-stained sections using a Zeiss (Thornwood, NY) Axioskop microscope equipped with a Ludl Mac 2000 automated stage and Sony XC-77 CCD camera and the Neurozoom software package (C) The Scripps Research Institute, San Diego, CA and Mt. Sinai School of Medicine, New York, NY, 1997).

Estimates of the volumes of the cuneate nucleus $(\mathrm{CN})$, external cuneate nucleus (ECN), gracile nucleus (GN), and VPL nucleus on the normal and deafferented sides were made using the method of Cavaleri (Mayhew 1992). Using a $2.5 \times$ objective, the borders of the nuclei were outlined in the thionin- and CO-stained serial sections. The anteroposterior extents of the nuclei were measured from the series of sections. In animals in which the border between VPL and the adjacent ventral posterior medial (VPM) nucleus had broken down, the medial border of VPL was estimated from the outline of the CO-dense staining of VPM. The anterior border of VPL was distinguished from the adjoining ventral lateral posterior (VLp) nucleus on the basis of the larger cells in VLp and the denser $\mathrm{CO}$ staining of VPL.

Estimates of neuron number in each nucleus were obtained using the optical disector method (Gundersen et al., 1988; West, 1993) and fractionator sampling protocol. Ten percent of the area of each outlined nucleus was sampled in a randomly generated grid under a $63 \times(1.4$ numerical aperture) oil immersion objective. Neuronal nuclei coming into focus over a succession of $2 \mu \mathrm{m}$ focal steps were marked and tabulated. Final neuron number estimates were calculated using the formula outlined by Mayhew (1992). All neurons were clearly distinguishable from neuroglial cells by size ( $>8 \mu \mathrm{m}$ in somal diameter) and morphological appearance.

Measurements of neuron size (by volume) were generated using the nucleator protocol (Gundersen et al., 1988) on $\sim 50 \%$ of the total number of neurons tabulated. Identified nucleoli were marked, and two perpendicular lines centered at the nucleolus were randomly superimposed over the neuron. The points at which each line crossed the outer surface of a neuronal nucleus were marked, and the software provided a volume measurement for that neuron. The volumes of the neuronal nuclei were added together for each section analyzed and then divided by the total number of neurons measured to obtain the mean of cell nucleus volume in the DCN or VPL.

Estimates of neuronal density were obtained for each nucleus by dividing the total estimated number of neurons by the measured volume of the nucleus. Quantitative estimates performed on sections from nuclei of the deafferented side were compared with those from nuclei on the unaffected side in the same animal, using Student's paired $t$ test.

\section{RESULTS}

\section{Qualitative observations}

Examination of $\mathrm{CO}$ - and thionin-stained sections through the spinal cord, medulla oblongata, and thalamus provided qualitative evidence that subcortical nuclei receiving sensory input from the upper limb and upper part of the trunk were profoundly affected by the chronic dorsal rhizotomies (Fig. 1). Brainstem nuclei ipsilateral to the rhizotomies and thalamic nuclei contralateral to the rhizotomies are referred to as affected or deafferented. Atrophic changes in the neurons of the deafferented DCN and 
PARV.

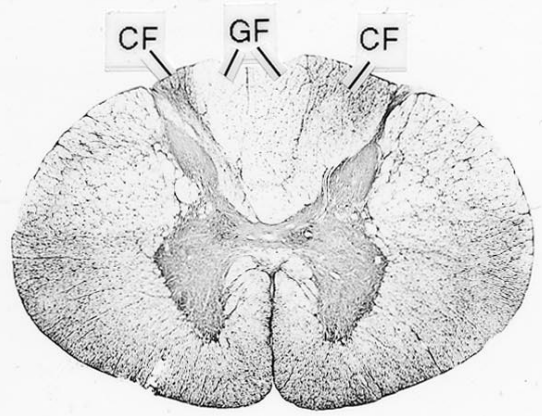

MAP2

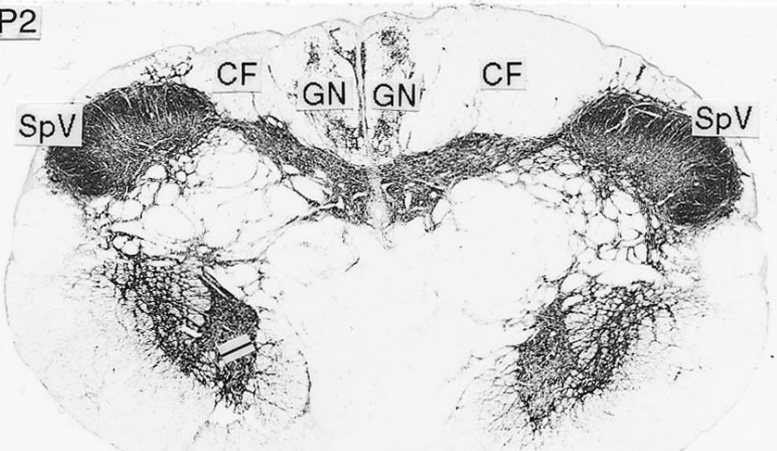

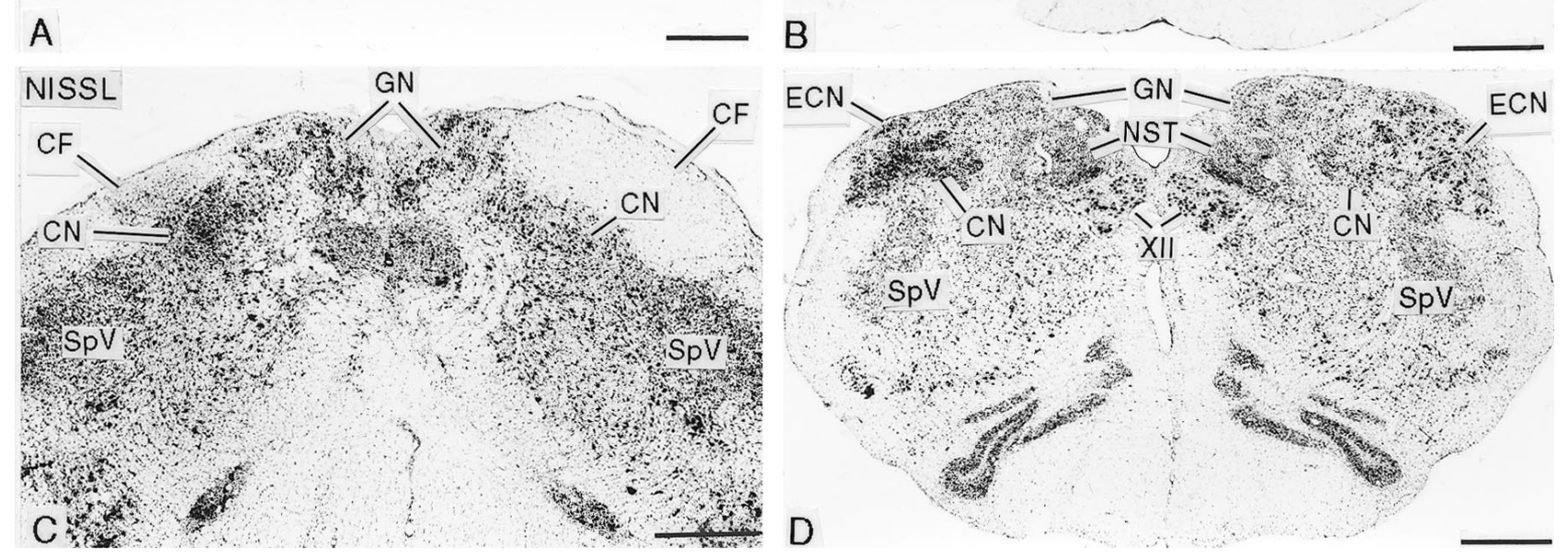

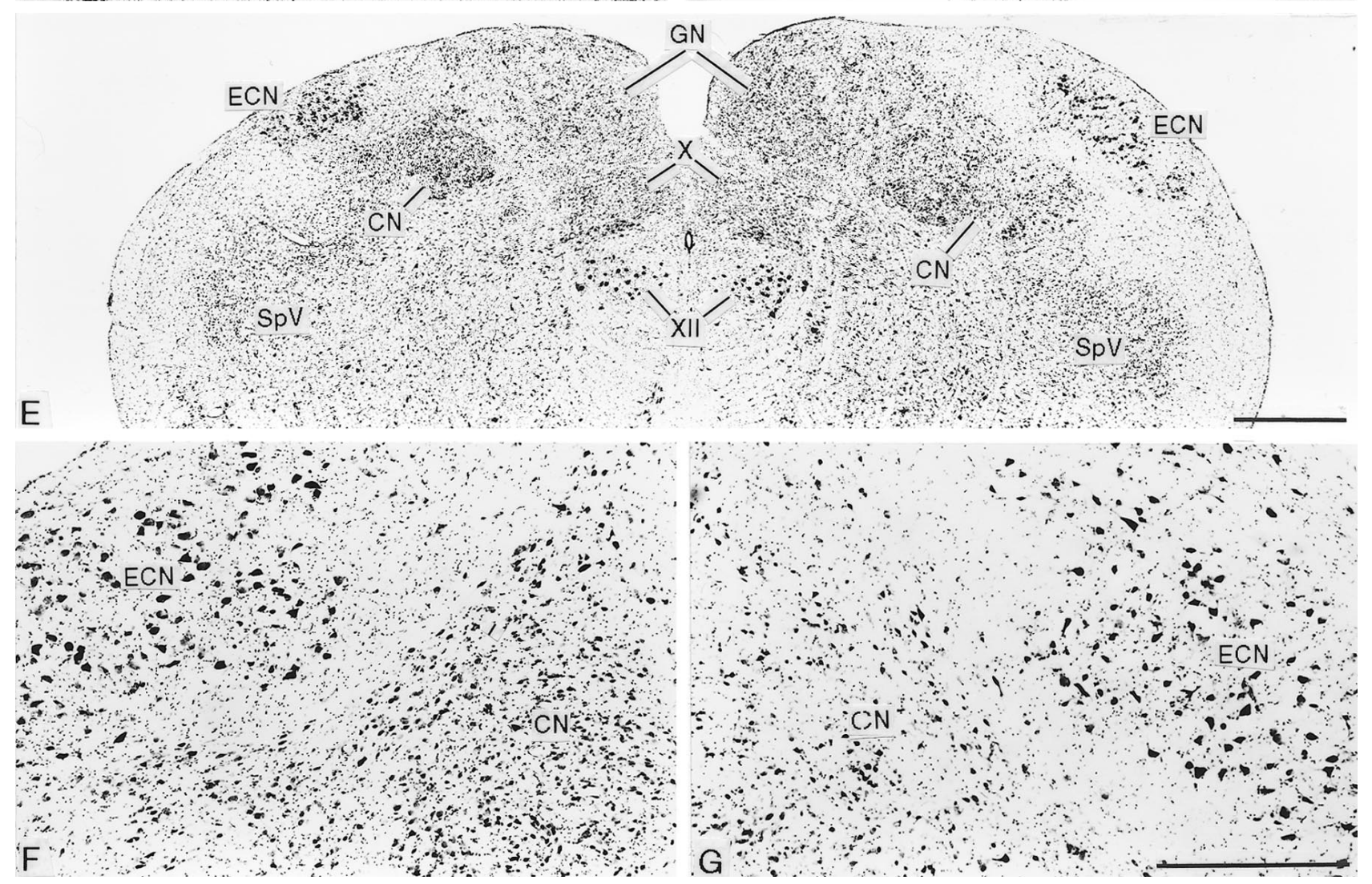

Figure 1. Photomicrographs showing the effects of long-standing unilateral rhizotomies on the spinal cord and dorsal column nuclei. $A$, Cross section of the first cervical segment of the spinal cord, stained for parvalbumin immunoreactivity (PARV.), from a monkey that survived for 14.3 years after rhizotomy. The cuneate fasciculus $(C F)$ on the operated side $(l e f t)$ is greatly shrunken, and there is displacement of the gracile fasciculi $(G F)$ to the left. $B$, Cross section at the spinomedullary junction, stained immunocytochemically for microtubule-associated protein 2 ( $M A P 2)$, from an animal that survived for 14.3 years after rhizotomy, showing reduction in size of the cuneate fasciculus $(C F)$ on the operated (left) side. (Figure legend continues) 
VPL are referred to as transneuronal atrophy and are apparent at all survival times (Table 1). As survival time increased, there was a general trend for the changes in the deafferented DCN and VPL to become more severe.

The ipsilateral cuneate fasciculus, through which the central axons of dorsal root ganglion cells innervating the upper limb run under normal conditions, was severely shrunken at all survival times, leading to distortion of the spinal cord with displacement of the two gracile fasciculi across the midline (Fig. $1 A$ ), and to distortion of the cross-sectional outline of the caudal medulla (Fig. $1 B-E$ ). There was obvious gliosis in the remaining portion of the affected cuneate fasciculus as it entered the medulla (Fig. 1C).

At all survival times, the ipsilateral $\mathrm{CN}$, especially the pars rotunda portion, containing the principal representation of the hand (Florence et al., 1989, 1991; Xu and Wall, 1996, 1999b), and the ipsilateral ECN, which also receives primary afferents from the upper limb and projects to the cerebellum, were distinctly shrunken in comparison with the opposite (normal) side (Fig. $1 C-G)$. The packing density of neurons within the deafferented $\mathrm{CN}$ and ECN was greatly increased compared with the normal side (Fig. $1 C-G)$. Packing density was greatest in the animal deafferented for 21.2 years (see below). Gliosis was evident in the deafferented $\mathrm{CN}$ and $\mathrm{ECN}$ at all survival periods (Fig. $1 C-F$ ). The GN and spinal trigeminal nuclei, whose afferents were not interrupted, were normal in size and anteroposterior extent in all animals (Fig. $1 B-E$ ). In the upper medulla and pons, there was a loss of immunostaining for parvalbumin fibers in the medial lemniscus contralateral to the affected $\mathrm{CN}$ (Fig. 2). This was apparent in animals at all survival times and was accompanied by immunostaining of astrocytes.

At all survival times studied, the contralateral VPL nucleus was smaller than the ipsilateral (normal) nucleus (Figs. 3, 4). This was especially apparent when comparing the anteroposterior extents of the two nuclei in sections cut symmetrically through the two sides of the diencephalon (Fig. 4). In the longest surviving animal, the affected VPL nucleus was at least $0.75 \mathrm{~mm}$ shorter in anteroposterior extent than the unaffected nucleus. Sections stained for $\mathrm{CO}$ or the calcium-binding proteins revealed a narrowing of the posterior pole of VPL with a lack of definition of the borders of the adjacent VPM nucleus (Figs. 3, 4). On progressing anteriorly in a series of frontal sections, the part of VPL lying between the arcuate lamella (which separates VPM from VPL) and the incomplete lamella separating the upper and lower limb representations in VPL was visibly paler than its surroundings in CO-stained sections (Figs. 3, 5) and lacked parvalbumin immunoreactivity in sections stained immunocytochemically for that calcium-binding protein (Fig. 3). This paler or unstained region was continuous through an interruption in the outline of the posterior pole of VPM with the CO-weak small-celled (S) region of VPM (Rausell and Jones, 1991) (Figs. 4, 5). When stained immunocytochemically for calbindin, the $\mathrm{S}$ region, much of the weaker stained medial region of VPL, and the zone of continuity between them were filled continuously with the densely calbindin-immunoreactive cells

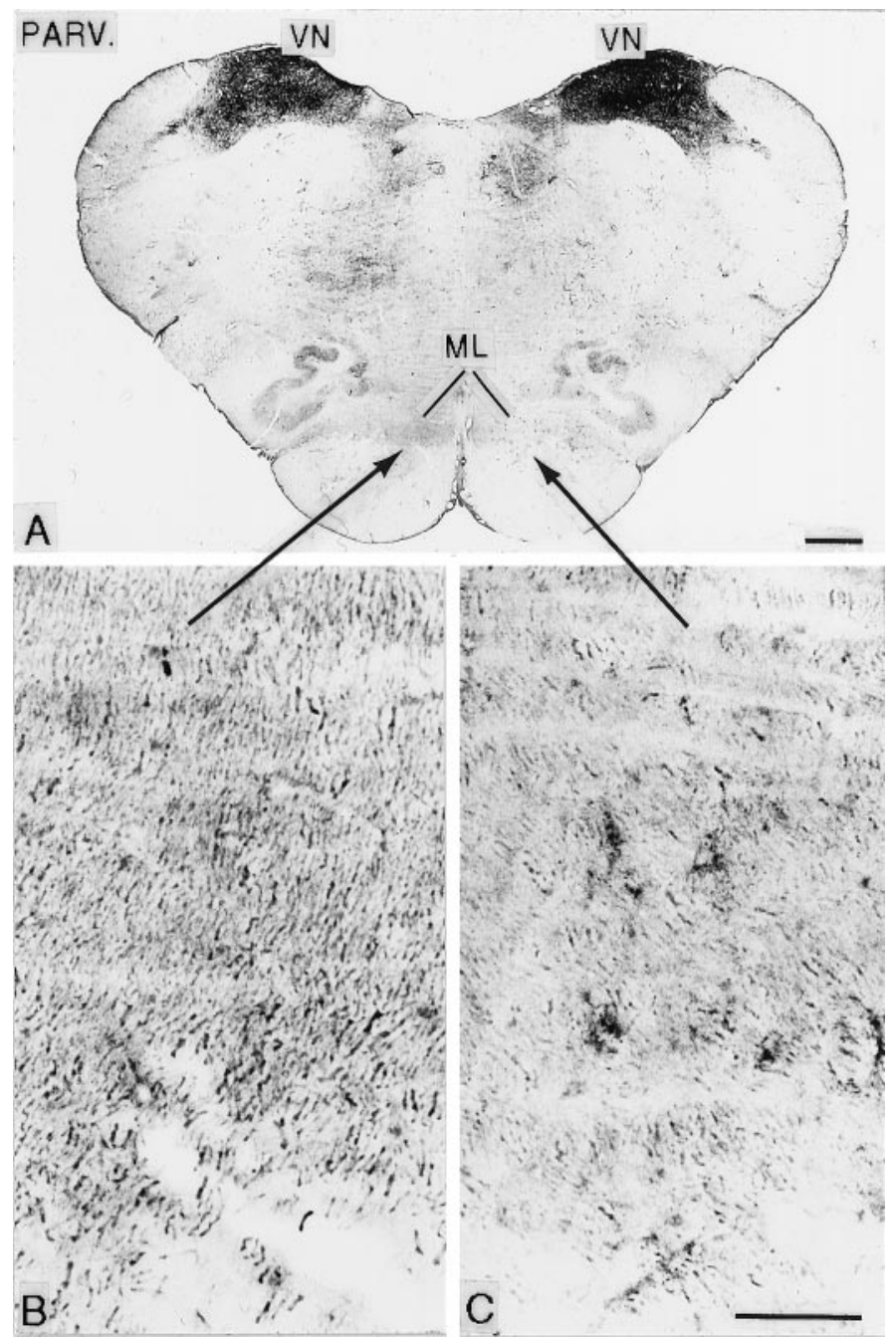

Figure 2. A, Cross section of the rostral medulla, stained for parvalbumin immunoreactivity $(P A R V$.), from an animal that survived for 12.8 years after rhizotomy. Areas indicated by arrows are enlarged in $B$ and $C$ and show loss of parvalbumin immunoreactivity, indicative of loss of fibers in the medial lemniscus $(M L)$ of the side $(C)$ contralateral to the rhizotomies. $V N$, Vestibular nuclei. Scale bars: $A, 1 \mathrm{~mm} . B, 100 C, \mu \mathrm{m}$.

typical of the $\mathrm{S}$ region and the adjoining anterior pulvinar and posterior nuclei (Fig. 5). Because of the foreshortening of the whole ventral posterior (VP) complex on the affected side, symmetrically cut frontal sections of the two sides gave an appearance of the calbindin-rich regions having expanded on the affected side (Fig. 6). These changes were apparent at all survival times but were most pronounced in the longest surviving animal.

At the shortest survival times (12.8-13.7 years), the arcuate lamella between the pale and visibly shrunken medial part of VPL was intact throughout most of the anteroposterior extent of the VP complex but was visibly thinned (Fig. 3). At intermediate

$C$, Nissl-stained cross section through the caudal aspects of the dorsal column nuclei in an animal that survived for 21.2 years after rhizotomy, showing shrinkage and gliosis of the cuneate fasciculus $(C F)$ and cuneate nucleus $(C N)$ on the operated (left) side. $D$, Nissl-stained cross section through the rostral aspects of the dorsal column nuclei in an animal that survived for 21.2 years after rhizotomy, showing shrinkage and gliosis of the cuneate nucleus $(C N)$ and external cuneate nucleus $(E C N)$ on the operated (left ) side. $E$, Nissl-stained cross section through the medulla of an animal that survived for 13 years after rhizotomy, showing shrinkage and increased cell density of the cuneate nucleus $(C N)$ and external cuneate nucleus $(E C N)$ on the operated (left) side. $F, G$. Higher-magnification photomicrographs from a section adjacent to $E$, showing the increased cell density and accompanying gliosis of the cuneate nucleus $(C N)$ and external cuneate nucleus $(E C N)$ on the operated $(F)$ side in comparison with the normal $(G)$ side. NST, Nucleus of solitary tract; $S p V$, spinal trigeminal nucleus; $X$, dorsal vagal nucleus; $X I I$, hypoglossal nucleus. Scale bars: $A-E, 1 \mathrm{~mm} ; F, G, 0.5 \mathrm{~mm}$. 

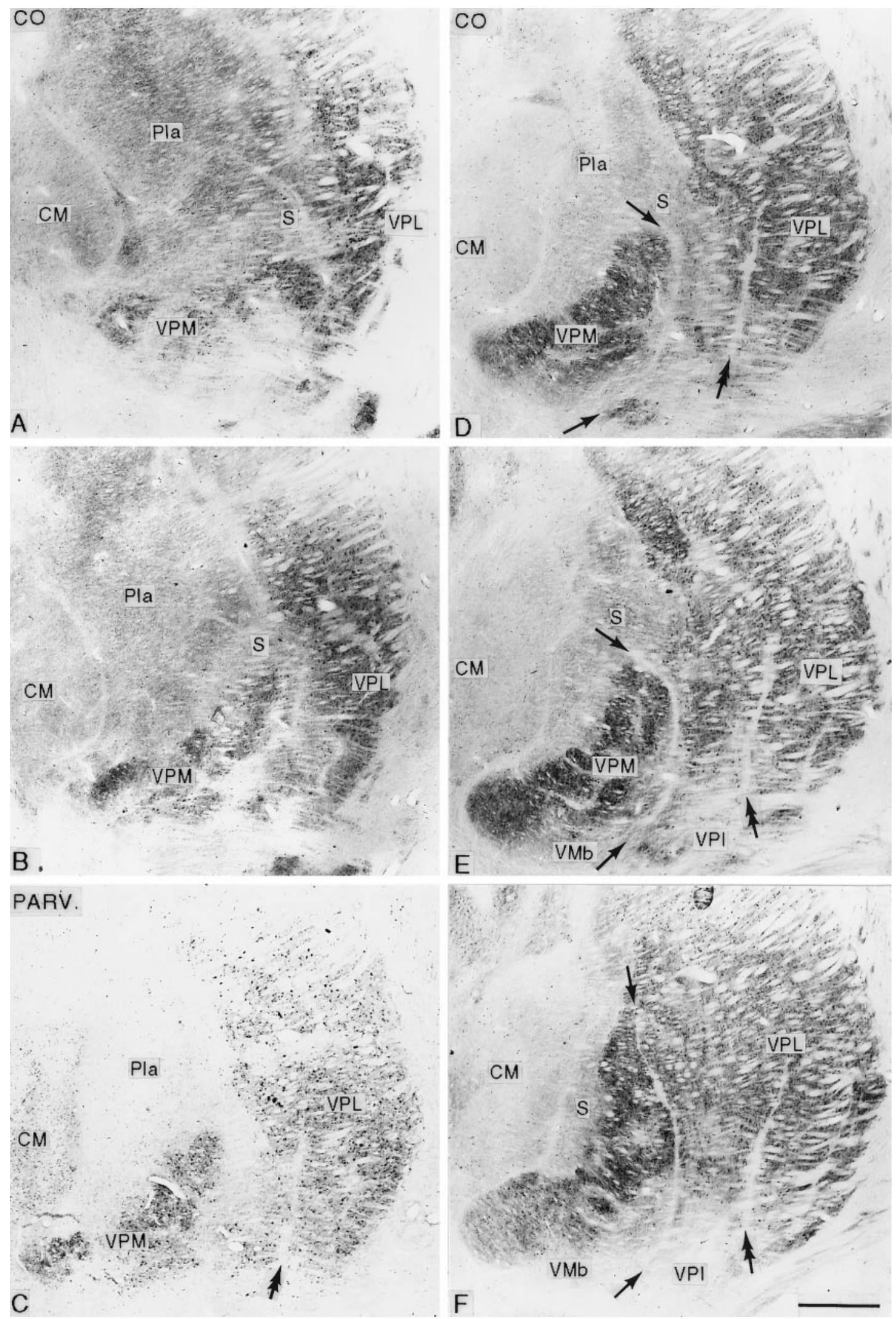

Figure 3. Series of frontal sections in posterior $(A)$ to anterior $(F)$ order, stained for cytochrome oxidase $(C O ; A, B, D-F)$ or immunocytochemically for parvalbumin $(P A R V$; $C)$, from the affected thalamus of an animal that survived for 12.8 years after rhizotomy, showing loss of the posterior part of the arcuate lamella (arrows) with disruption of the posterior part of the VPM nucleus and shrinkage, with pallor and loss of parvalbumin staining of the part of VPL between the arcuate lamella and the incomplete lamella (double arrow) that normally separates the upper and lower limb representations in VPL. $C M$, Centre médian nucleus; Pla, anterior pulvinar nucleus; $S$, small-celled region of VPM and posterior nucleus; $V M b$, basal ventral medial nucleus; $V P I$, ventral posterior inferior nucleus. Scale bar, $1 \mathrm{~mm}$. 


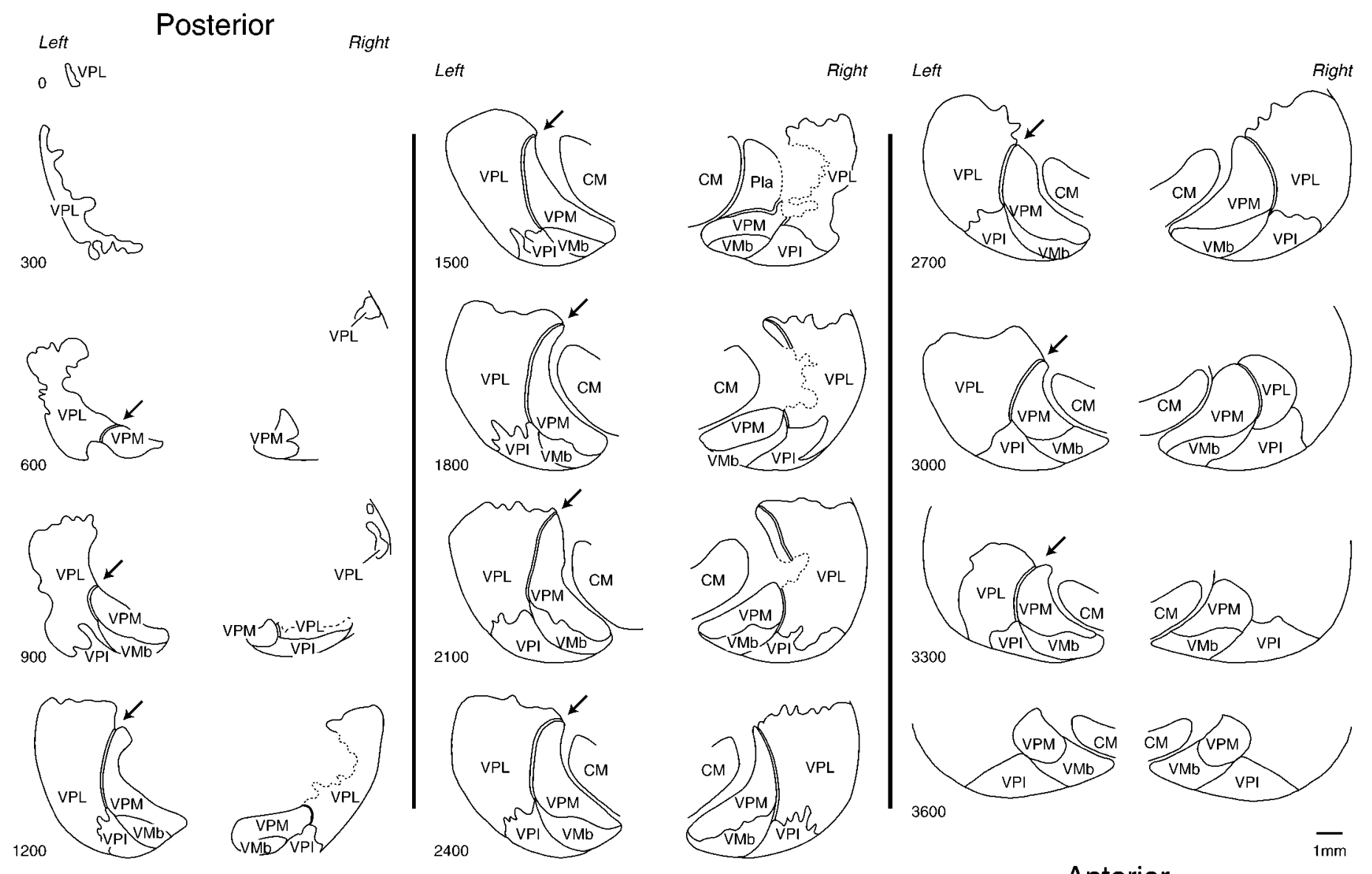

Anterior

Figure 4. Columns (left, middle, right) of paired camera lucida drawings at $300 \mu \mathrm{m}$ intervals (numerals at bottom left) from symmetrically cut frontal sections of the diencephalon in an animal that survived for 21.2 years after rhizotomy, showing the posterior-to-anterior extent of the ventral posterior nuclear complex of the thalamus ipsilateral (left) and contralateral (right) to the rhizotomies. On the affected (right) side, there is foreshortening of the VPL nucleus and loss of the posterodorsal part of the arcuate lamella (interrupted line) that normally (arrows) separates the VPM nucleus from VPL. $C M$, Centre médian nucleus; Pla, anterior pulvinar nucleus; $V M b$, basal ventral medial nucleus; $V P I$, ventral posterior inferior nucleus.

survival times (14.3-15.1 years), it had broken down in its posterior half, and the dense CO-stained VPM nucleus had invaded the pale part of VPL (Fig. 7). Anteriorly, however, the arcuate lamella was reconstituted, although thinner. At the longest survival (21.2 years), the posterior half of the arcuate lamella was lost altogether, and in this region VPM and the medial part of VPL had merged so completely that it was difficult to tell where one ended and the other began (Fig. 4). Anteriorly, the borders of the two subnuclei were restored, although the arcuate lamella remained much thinner than normal.

When studied in thionin-stained preparations, many neurons in the deafferented part of VPL appeared smaller than normal, giving this part of VPL a paler appearance than the remainder of VPL when viewed at low magnification (Fig. 8A). At higher magnification, however, it could be seen that the smaller neurons were more densely stained than normal, and their packing density was increased. (No neurons were sufficiently shrunken to be mistaken for neuroglial cells.) In addition, and especially in the animal surviving for 21.2 years, they were mixed with a significant number of larger neurons resembling those of the unaffected lateral part of VPL (Fig. $8 B$ ). The overall appearance of the disorganized ventral posterior nuclear complex suggested that loss of the posterodorsal portion of the arcuate lamella had facilitated the collapse of the posterior portion of VPM (whose innervation from the trigeminal pathways had presumably remained intact) into the area of the former upper limb-upper trunk representation in VPL, a suggestion supported by receptive field mapping in the disorganized region in which cells with receptive fields on the face could lie adjacent to those with receptive fields on the lower limb (Jones and Pons, 1998), a feature never found in normal monkeys.

\section{Quantitative observations}

Qualitative observations were confirmed quantitatively. The overall volume of the affected CN, ECN, and VPL, as well as the numbers of neurons and their sizes were reduced at all survival times studied, and neuronal packing was increased. As survival time after rhizotomy increased, there was a general trend for the volume of the deafferented CN, ECN, and VPL nuclei and the number and sizes of their neurons to become progressively reduced (see below and Figs. 9-11). Summed values from the deafferented nuclei were compared with values from the equivalent nuclei on the opposite (normal) side of the same monkey and are reported as a percentage of normal. Thus, $-10 \%$ indicates a $10 \%$ reduction in a deafferented nucleus in comparison with the nucleus of the unaffected side. 

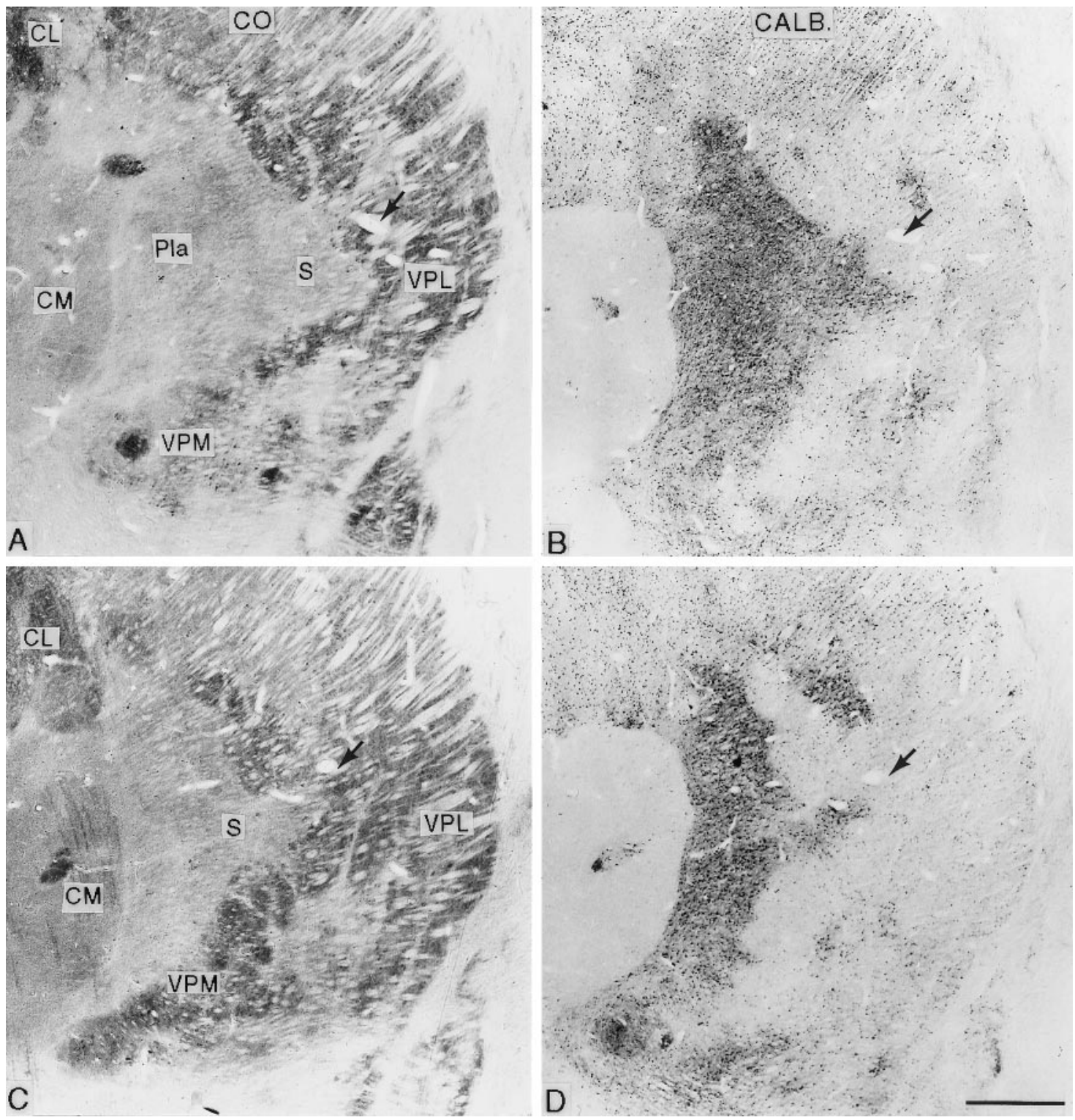

Figure 5. Pairs of adjacent frontal sections stained for cytochrome oxidase $(C O ; A, C)$ or immunocytochemically for calbindin $(C A L B$.; $B, D)$ from the affected thalamus of an animal that survived for 13.7 years after rhizotomy $(A, B$ are posterior to $C, D)$, showing the shrinkage of VPL with pallor of its medial part in the cytochrome oxidase sections, loss of the arcuate lamella, and expansion of the cytochrome oxidase-weak and calbindin-rich $\mathrm{S}$ region into the affected area. Arrows indicate the same blood vessel. $C L$, Central lateral nucleus; $C M$, centre médian nucleus; Pla, anterior pulvinar nucleus; $S$, small-celled region of VPM and posterior nucleus; $V M b$, basal ventral medial nucleus; VPI, ventral posterior inferior nucleus. Scale bar, 1 mm.

\section{Volumes of DCN}

The volume of the ipsilateral $\mathrm{CN}$ was reduced in all cases studied, ranging from $44.12 \%$ smaller than the normal side in case 4 to $51.38 \%$ smaller than normal in case 7 , with the longest survival time (Fig. 9). The magnitude of volume loss (Fig. 9) ranged from $45.88 \%$ after 12.8 years (case 1 ) to $51.38 \%$ after 21.2 years (case 7). The mean decrease in volume in the ipsilateral CN compared with the normal sides across all seven cases was $47.55 \pm 2.85 \%$ $(p \leq 0.01)$ (Fig. 10).

The volume of the ipsilateral ECN was also reduced in all cases, the reduction ranging from $36.95 \%$ (case 1 ) to $47.81 \%$ (case 7) in comparison with the normal side (Fig. 9). Across all seven cases, the ipsilateral ECNs were on average $43.07 \pm 4.00 \%(p \leq$ 0.01) smaller than those of the contralateral sides (Fig. 10). Any differences in the volumes of the GNs on the ipsilateral and contralateral sides were not significant at any of the survival times studied (Fig. 9). The ipsilateral GNs were on average $1.85 \pm$ $3.45 \%$ smaller than the contralateral GNs, but this difference was not statistically significant $(p \leq 0.10)$ (Fig. 10).

\section{Loss of neurons in DCN}

Table 1 shows the estimated number of neurons in the $\mathrm{CN}, \mathrm{ECN}$, and GN from each case. Despite the considerable reduction in the overall volume of the deafferented CN (Fig. 9), the number of neurons was reduced by only $9.45 \%$ after 12.8 years (case 1 ), $8.37 \pm 1.75 \%$ after 13.7 years (mean of cases $2-4), 11.51 \pm 1.82 \%$ after 14.3 years (mean of cases 5 and 6 ), and $15.31 \%$ after 21.2 years (case 7). Overall, the seven cases showed a mean $10.34 \pm$ $2.84 \%(p \leq 0.01)$ reduction in the number of neurons in the deafferented $\mathrm{CN}$ in comparison with the $\mathrm{CN}$ of the unaffected side (Fig. 10).

Table 1 also shows the estimated number of neurons in the 


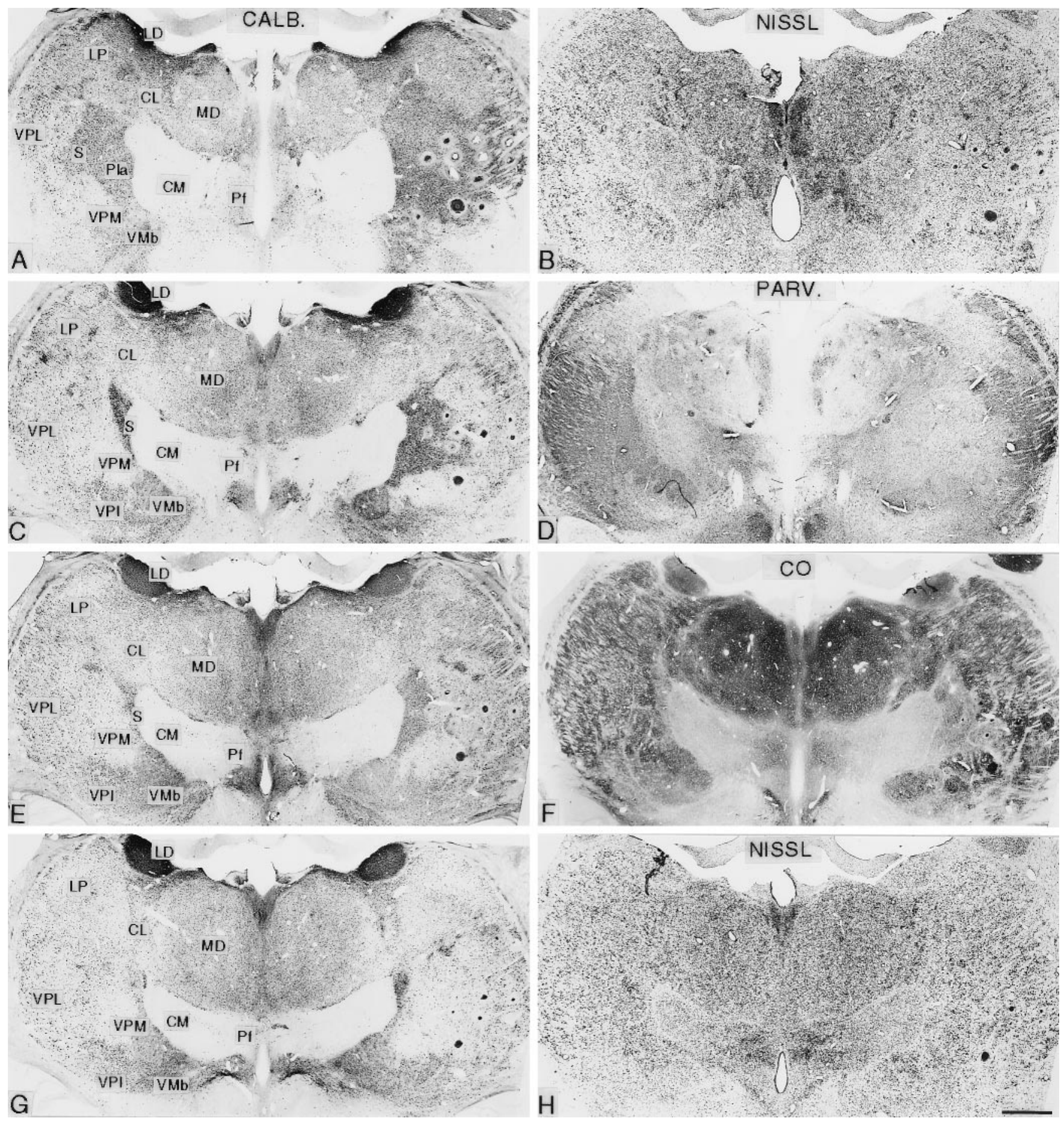

Figure 6. Pairs of symmetrically cut frontal sections of the diencephalon in posterior $(A, B)$ to anterior $(G, H)$ order from an animal that survived for 21.2 years after rhizotomy. The left member of each pair is stained immunocytochemically for calbindin $(C A L B ; A, C, E, G)$, and the other is stained either by the Nissl method $(B, H)$, immunocytochemically for parvalbumin $(P A R V$.; $D)$, or for cytochrome oxidase $(C O ; F)$. These show the ventral posterior nuclear complex of the thalamus ipsilateral (left) and contralateral (right) to the rhizotomies. On the affected (right) side, there is foreshortening of the VPL nucleus and loss of the posterodorsal part of the arcuate lamella that normally separates the VPM nucleus from VPL. There is expansion of the calbindin-rich $\mathrm{S}$ region into the area formerly occupied by the affected part of the ventral posterior complex. $C L$, Central lateral nucleus; $C M$, centre médian nucleus; $L D$, lateral dorsal nucleus; $L P$, lateral posterior nucleus; $M D$, mediodorsal nucleus; $P f$, parafascicular nucleus; $P l a$, anterior pulvinar nucleus; $V M b$, basal ventral medial nucleus; VPI, ventral posterior inferior nucleus. Circular profiles in right thalamus are microelectrode tracks. Scale bar, $1 \mathrm{~mm}$.

ECN and GN. The number of neurons in the deafferented ECN decreased from $7.98 \%$ fewer than on the normal side after 12.8 years to $16.98 \%$ fewer after 21.2 years (Fig. 9). The mean decrease in neuron number in the ipsilateral ECN across all seven cases was $9.61 \pm 4.79 \%$ ( $p \leq 0.01$ ) (Fig. 10). In the GN, overall, there were $0.19 \%$ more neurons on the deafferented side than on the normal side, but this difference was statistically insignificant $(p>0.1)$ (Fig. 10). 

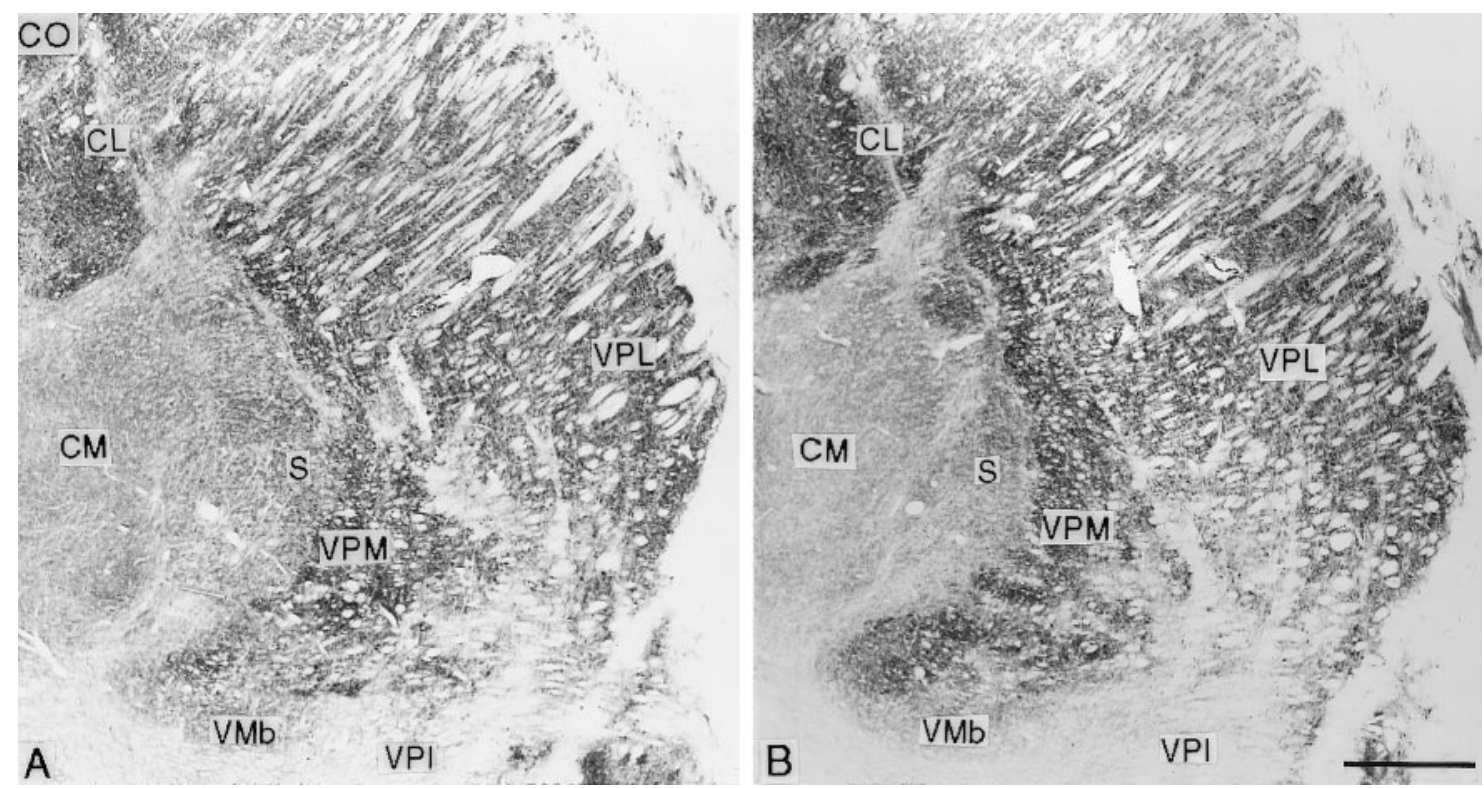

Figure 7. Frontal sections stained for cytochrome oxidase $(C O ; A$ is posterior to $B)$ from the affected thalamus of an animal that survived for 15.1 years after rhizotomy, showing loss of the arcuate lamella and expansion of VPM into the pale and shrunken medial part of VPL. $C L, C$ entral lateral nucleus; $C M$, centre médian nucleus; Pla, anterior pulvinar nucleus; $V M b$, basal ventral medial nucleus; $V P I$ ventral posterior inferior nucleus. Scale bar, 1 mm.

\section{Atrophy of DCN neurons}

Table 2 shows the sizes (by volume) of neuronal somata in the DCN. Neurons in the affected CN and ECN were smaller than on the normal side in all cases, whereas neurons in the GN of both sides remained consistently the same. The magnitude of the reduction in neuronal size in the affected $\mathrm{CN}$ increased linearly with survival time (Figs. 9, 10). Figure 9 shows that 12.8 years after rhizotomy (case 1), neurons were $10.92 \%$ smaller than on the normal side; after 13.7 years (mean of cases 2 and 3 ) neurons were $11.22 \%$ smaller; after 14.3 years (case 4) neurons were $15.09 \%$ smaller; after 15.1 years (mean of cases 5 and 6 ) neurons were $18.54 \%$ smaller; and after 21.2 years (case 7 ) neurons were $44.63 \%$ smaller than on the normal side. Figure 10 shows that, overall, the mean decrease in neuron volume in the affected $\mathrm{CN}$ in comparison with the normal side was $19.43 \pm 12.55 \%$ $(p \leq 0.01)$.

Neuronal somata in the affected ECN were also reduced in size in comparison with the normal side (Table 2). After 12.8 years, neurons in the ECN were $9.00 \%$ smaller than neurons on the normal side, and after 21.2 years neurons were $28.21 \%$ smaller, the decrease in size progressing with survival time after rhizotomy (Fig. 9). Overall, the mean decrease in somal size in the ipsilateral ECN was $14.32 \pm 6.62 \%(p<0.01)$ (Fig. 10). In the $\mathrm{GN}$, neurons on the affected and unaffected sides showed no variation in size across all seven cases (Fig. 9). Although the mean size of neurons in the GN ipsilateral to the rhizotomies was $0.71 \pm 0.55 \%$ less than on the contralateral side, this difference was not statistically significant $(p>0.1)$ (Fig. 10).

\section{Increase in neuronal density in DCN}

Table 3 shows the packing density of neurons in the DCN in each case. Concomitant with the large decrease in the volumes of the affected $\mathrm{CN}$ and ECN and the relatively small reduction in the number of neurons in these nuclei, the packing density of neurons in the affected $\mathrm{CN}$ and ECN was increased (Fig. 9), in the $\mathrm{CN}$ ranging from $67.38 \%$ more neurons per unit volume after 12.8 years (case 1) to $74.89 \%$ after 21.2 years (case 7) (Fig. 9). Overall, the mean increase in neuron density in the affected $\mathrm{CN}$ was $78.44 \pm 6.85 \%(p \leq 0.01)$ (Fig. 10).

In the ECN ipsilateral to the rhizotomies, there was an increase in neuron density ranging from $47.45 \%$ in case 1 to $69.11 \%$ in case 7 (Fig. 9), with a mean increase overall of $59.65 \pm 7.94 \%$ ( $p \leq$ 0.01 ) (Fig. 10). In the GN, the mean density of neurons on the ipsilateral side was $2.60 \pm 4.17 \%$ greater than on the contralateral side, but this difference was not statistically significant $(p>0.1)$ (Fig. 10).

\section{Volume of VPL}

The VPL nuclei on the affected and unaffected sides of the brain were measured in cases 1,2 , and 7 , with survival times of 12.8 , 13.7, and 21.2 years after rhizotomy (Table 4 ). The volume of the affected VPL was smaller than the normal in each case (Fig. 11). After 12.8 years, the volume of the affected VPL was $32.05 \%$ smaller than the normal; after 13.7 years the volume was $32.65 \%$ smaller; and after 21.2 years the volume was $37.85 \%$ smaller, with a mean reduction in volume across all three cases of $34.33 \pm$ $3.19 \%(p \leq 0.01)$ (Fig. 11).

\section{Loss of neurons in VPL}

Table 4 shows the estimated number of neurons in VPL of the two sides for the three cases studied. There were fewer neurons in the affected VPL in comparison with the normal VPL. After 12.8 years, there were $14.37 \%$ fewer neurons than on the normal side; after 13.7 years there were $15.78 \%$ fewer; and after 21.2 years there were $20.51 \%$ fewer neurons than normal (Fig. 11). Overall, mean loss of neurons in the affected VPL was $17.01 \pm 3.21 \%$ $(p \leq 0.05)$ (Fig. 11).

\section{Atrophy of neurons in VPL}

Table 4 shows the sizes (by volume) of neuronal somata in VPL of both sides in the three cases. Somal size was reduced in the deafferented VPL in comparison with the normal side by $15.96 \%$ after 12.8 years, $11.11 \%$ after 13.7 years, and $21.73 \%$ after 21.2 years (Fig. 11). The mean reduction was $16.27 \%$ (Fig. 11). 


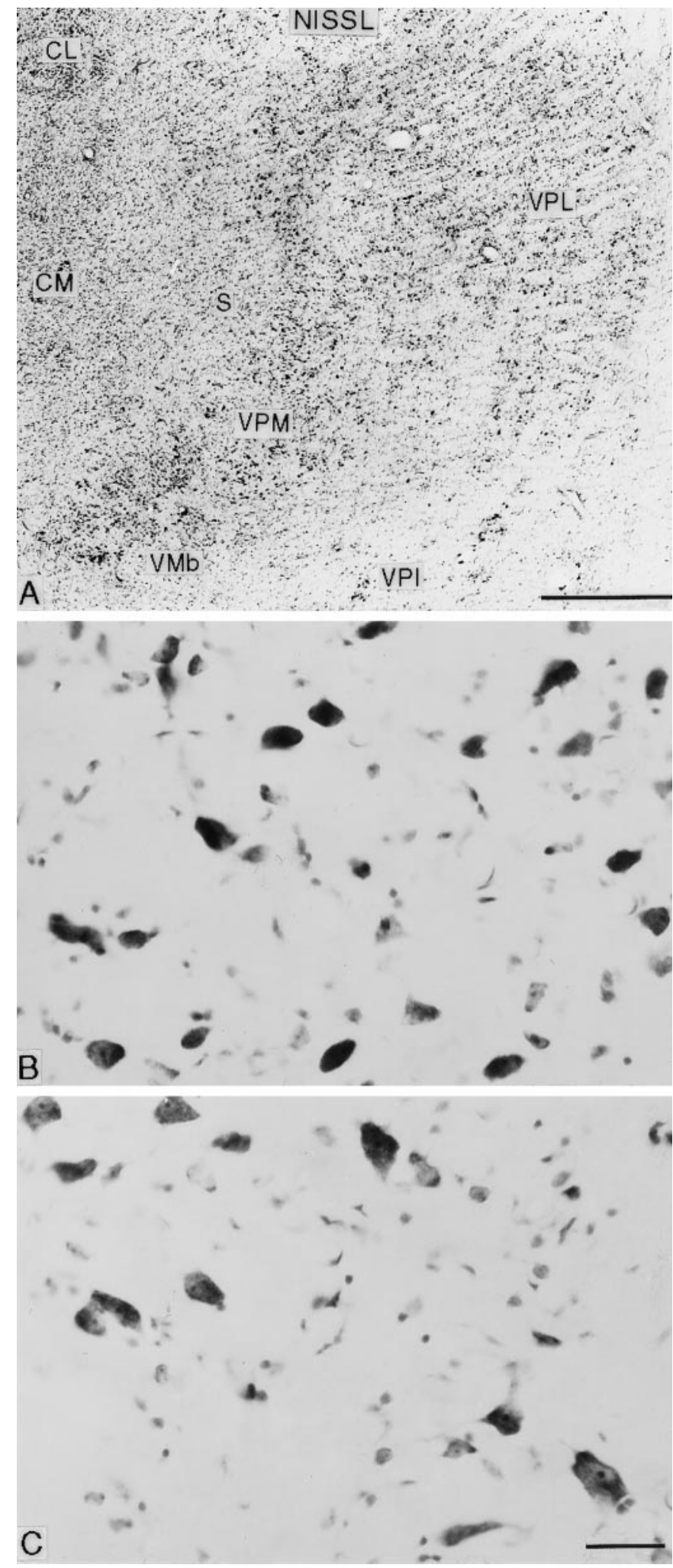

Figure 8. $A$, Nissl-stained frontal section through the ventral posterior complex of the affected thalamus from an animal that survived for 15.1 years after rhizotomy, showing the loss of the arcuate lamella between VPM and VPL and the pallor of the medial part of VPL. $B, C$. Highermagnification photomicrographs from the medial (deafferented upper limb representation; $B$ ) and lateral (intact, lower limb representation; $C$ ) parts of the same VPL nucleus, showing increased cell density and shrinkage of neurons in $B$ in comparison with $C$. Smallest profiles are neuroglial cells. Scale bars: $A, 1 \mathrm{~mm} ; B, C, 25 \mu \mathrm{m}$.

\section{Increase in neuron density in VPL}

Table 4 shows the packing density of neurons in VPL of both sides in the three cases. The large decrease in VPL volume and relatively small loss of neurons on the affected side were associated with an increase in neuronal packing density relative to the control side, ranging from $25.05 \%$ (case 2) to $27.90 \%$ (case 7 ) (Fig. 11). Overall, the mean increase in the density of neurons in the affected VPL was $26.31 \pm 1.45 \%(p \leq 0.01)$ (Fig. 11).

\section{Summary of results}

Long-term survival after destruction of primary afferents by dorsal rhizotomies from $\mathrm{C} 2$ through $\mathrm{T} 4$ revealed pronounced primary transneuronal effects in second-order neurons of the ipsilateral $\mathrm{CN}$ and $\mathrm{ECN}$ and similar secondary transneuronal effects in third-order neurons of the contralateral VPL. Over 12.8-21.2 years, these brainstem and thalamic nuclei showed reductions in volume and in neuronal size, increased neuronal packing density, and a relatively modest but progressive loss of neurons. The GN, which retained its afferent innervation, showed no significant differences in volume or in neuronal size, density, or number.

\section{DISCUSSION}

The changes wrought in the dorsal column nuclei by chronic deafferentation are manifestations of primary transneuronal atrophy; the comparable changes in the thalamus can be characterized as secondary transneuronal atrophy, not hitherto described in the somatosensory system.

Transneuronal atrophy (formerly called "transneuronal degeneration") is a long-recognized phenomenon in the lateral geniculate nucleus of monkeys, humans, and certain nonprimates after removal of an eye (Cook et al., 1951; Matthews et al., 1966). In monkeys, cells in deprived geniculate layers commence shrinking within $7 \mathrm{~d}$ and by 1 year are $50 \%$ reduced in size, but cell death is minimal (Matthews, 1964; Sloper et al., 1987), only becoming significant after many years (Goldby, 1957; Kupfer, 1965). In the brainstem, in monkeys 6 months after dorsal column transection, the gracile nucleus was reduced in size by $20 \%$, its cells shrunken by $25 \%$ but with only $13 \%$ loss of neurons (Loewy, 1973). Primary transneuronal atrophy also occurs in brainstem trigeminal and auditory nuclei after section of trigeminal or auditory nerves (Penman and Smith, 1950; Powell and Erulkar, 1962) and in the prepiriform cortex after olfactory bulbectomy (Matthews and Powell, 1962; Powell, 1967). It is thus ubiquitous and a potential contributor to activity-dependent reorganization of all sensory pathways.

Despite its inexorable nature, the primary and secondary transneuronal atrophy in the DCN and thalamus is accompanied by relatively little neuronal death, even after 21 years. The slow shrinkage of neurons may provide an impetus to reorganization of the deafferented nuclei. Neurons undergoing transneuronal atrophy subsequent to deafferentation show withdrawal and reduced branching of dendrites (Powell, 1967). Axons of atrophying cells are also likely to withdraw from their targets (lemniscal axons from thalamus and thalamic axons from cortex), as supported by the evidence of axon loss in the medial lemniscus and thinning of the arcuate lamella in the thalamus. Loss of activity is a powerful, rapid influence in causing retinogeniculate and geniculocortical axons to reduce the extent of their terminal ramifications (Sretevan and Shatz, 1986; Antonini and Stryker, 1993; Antonini et al., 1998, 1999). Similar withdrawal of axon terminations from parts of the body representation in VPL and 


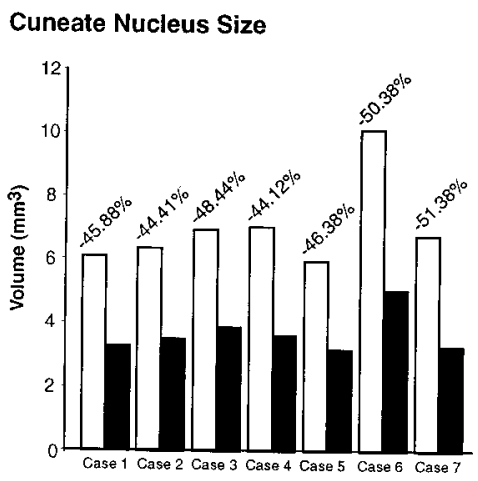

Cuneate Nucleus Neuron Size

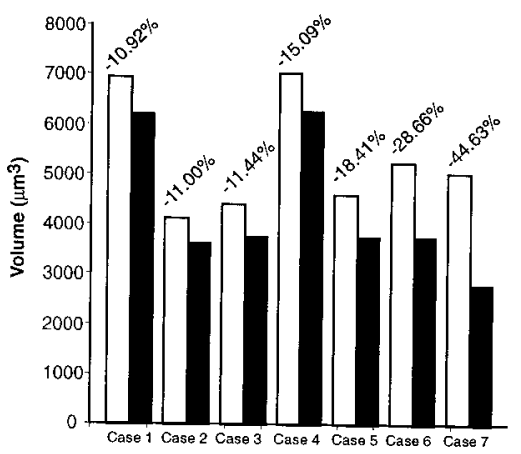

Cuneate Nucleus Neuron Number

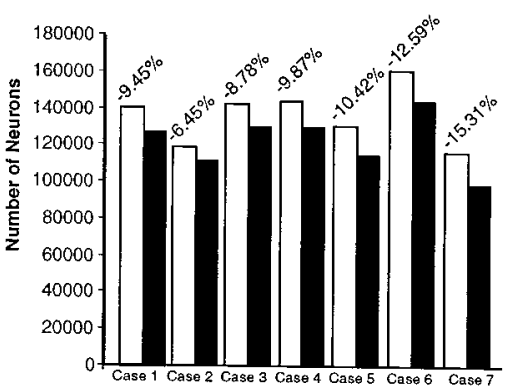

Cuneate Nucleus Neuronal Packing Density

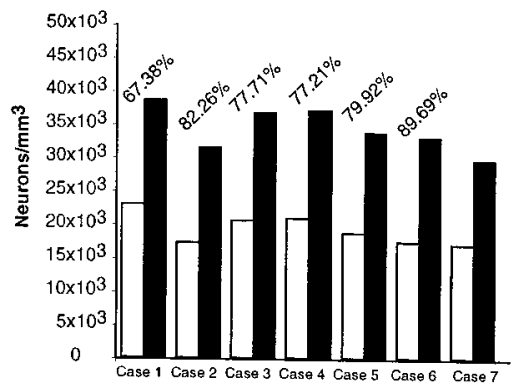

External Cuneate Nucleus Size

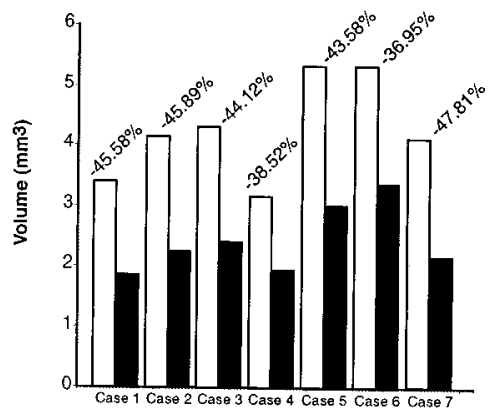

ECN Neuron Size

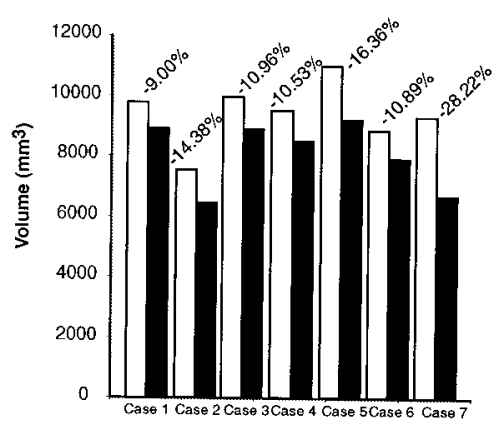

ECN Neuron Number

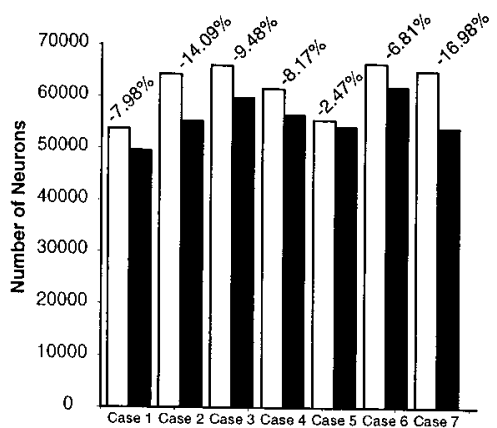

ECN Neuronal Packing Density

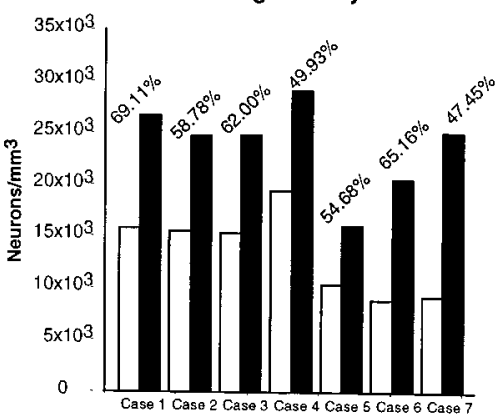

Gracile Nucleus Size $\quad$ Deafferented

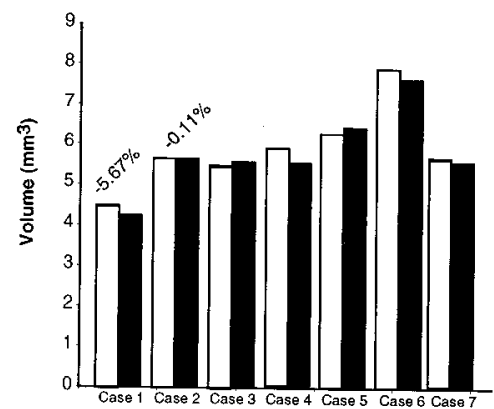

Gracile N. Neuron Size

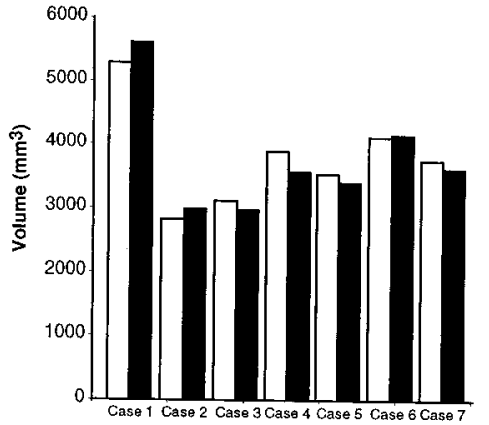

Gracile N. Neuron Number

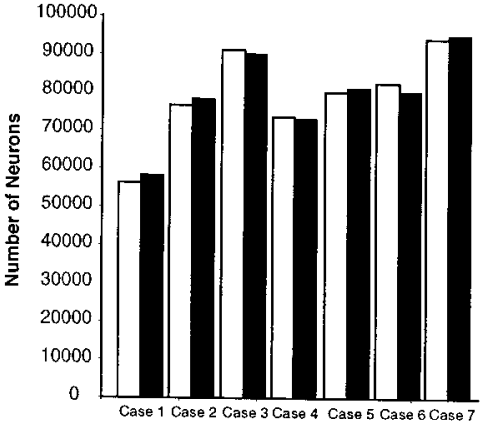

Gracile N. Neuronal Packing Density

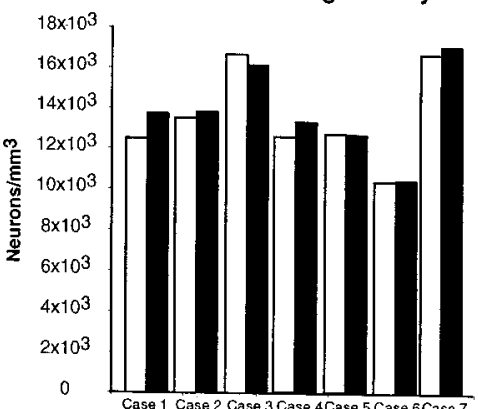

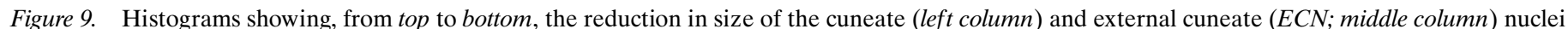

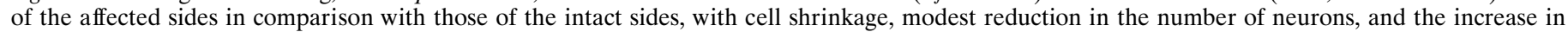

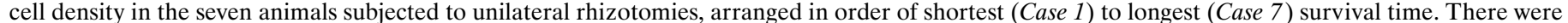
no corresponding changes in the gracile nuclei of either side (right column). 

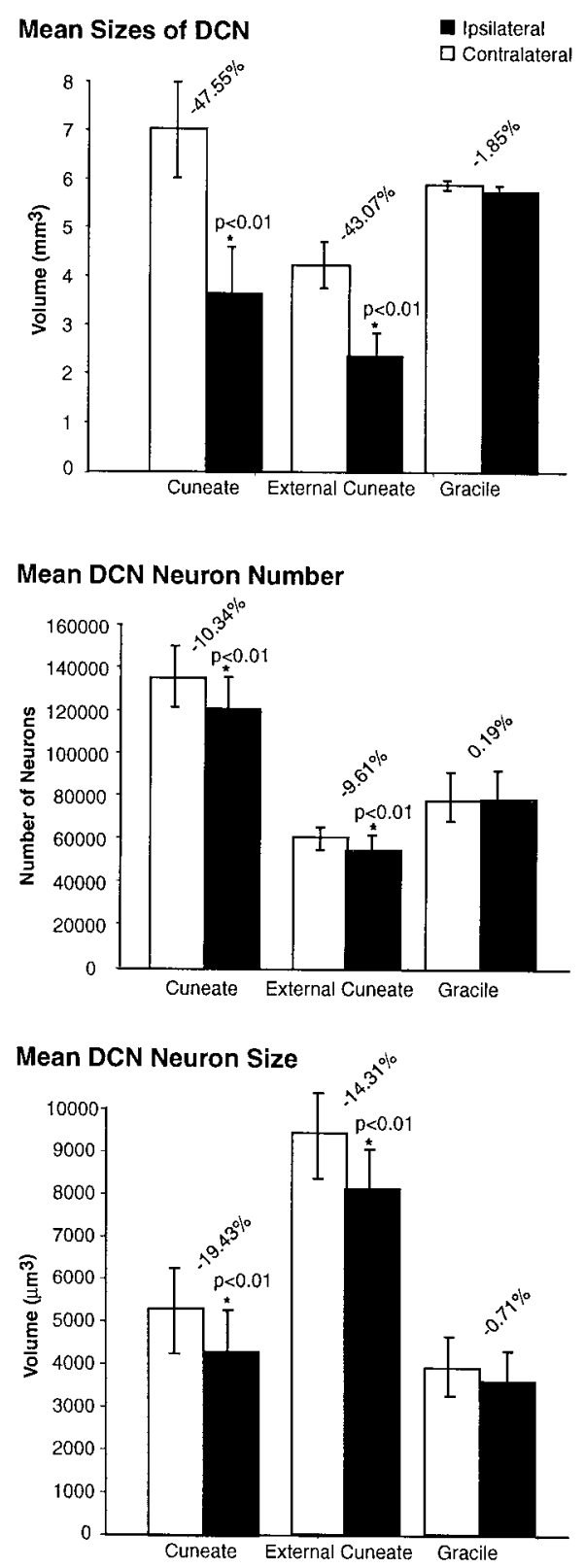

Mean DCN Neuronal Packing Density

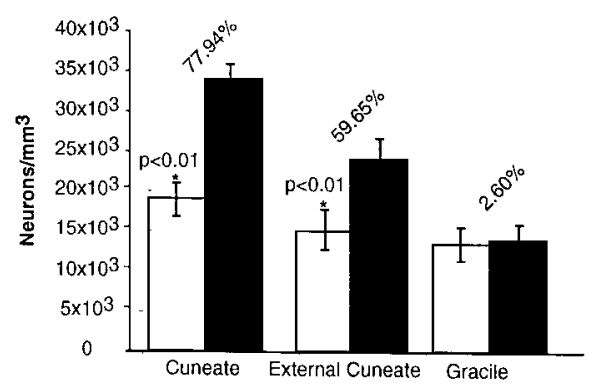

Figure 10. Histograms showing, from top to bottom, the mean reduction in size of the cuneate and external cuneate nuclei of the affected side in comparison with those of the opposite sides, with cell shrinkage, modest reduction in the number of neurons, and the increase in cell density in the seven animals subjected to unilateral rhizotomies, plus the lack of significant changes in the gracile nuclei. Error bars denote SD; *Significance at the $p$ value indicated. somatosensory cortex could represent a major stimulus to reorganization.

Functional reorganization occurs in the DCN and VPL after loss of primary afferents, in concert with the slow atrophy of brainstem and VPL cells. After partial deafferentation or temporary blocking of sensory inputs to the cuneate or gracile nuclei, deafferented cells in these nuclei immediately acquire larger or new receptive fields (Millar et al., 1976; Pettit and Schwark 1993; Panetsos et al., 1997; Xu and Wall, 1997, 1999a) (for negative results, see Northgrave and Rasmusson, 1996; Zhang and Rowe, 1997), and over time cells in silenced parts of the representation can be activated from regions of the body with intact innervation (Dostrovsky et al., 1976; Kalaska and Pomeranz, 1982; Rasmusson and Northgrave, 1997).

In the somatosensory thalamus, representations of body parts with intact innervation expand into parts of the representation silenced by central or peripheral deafferentation, even after survival times as short as 1 week, and remain over the long term (Wall and Egger, 1971; Lombard et al., 1979; Pollin and AlbeFessard, 1979; Garraghty and Kaas, 1991; Lenz et al., 1994; Rasmusson, 1996a). Emergence of new receptive fields, akin to that seen in the DCN (Pettit and Schwark, 1993), occurs immediately after injecting local anesthetic into the receptive fields of VPL neurons (Nakahama et al., 1966; Nicolelis et al., 1993; Shin et al., 1995; for negative results, see Rasmusson 1996b), and acute expansions of a VPL representation after lesions of the DCN continue to expand over the ensuing month (Parker et al., 1998). The largest expansion occurred in the monkeys from the present series in which, 21.2 years after deafferentation, the normally minute representation of the lower part of the face dominated the part of VPL affected by transneuronal atrophy (Jones and Pons, 1998b). We, therefore, propose that reorganization of brainstem and thalamic somatosensory relay nuclei occurs in two phases: an acute phase of receptive field expansion, presumably attributable to uncovering of previously masked divergent inputs to relay neurons, followed by a phase associated with internal reorganization of the nuclei that progresses continuously as deafferented cells wither and eventually die.

In the DCN and VPL, slow atrophy of silenced neurons should bring cells with intact innervation on either side of the affected representation closer together, with alteration in topographic maps at all levels, up to and including the cortex. Withdrawal of axons of atrophying DCN neurons from part of VPL, and of axons of secondarily affected VPL cells from the cortex, is also likely to permit the normally divergent lemniscal and thalamocortical connectivity (Rausell and Jones, 1995; Rausell et al., 1998; Jones, 2000) to manifest itself so that previously silent inputs from body regions with intact innervation to affected parts of a representation will now be revealed, leading to alterations in topographic maps in thalamus and cortex. The atrophy of afferent axons and silenced cells might also induce sprouting of intact afferent fiber ramifications in brainstem, thalamus, and cortex. Expansion of terminal ramifications of intact afferents has been described in the DCN of monkeys after section and regeneration of peripheral nerves (Florence et al., 1994; Florence and Kaas, 1995; Lekan et al., 1997). However, the expansion is not sufficiently extensive to explain the massive reorganization occurring in the thalamus and cortex of the present monkeys. Sprouting of lemniscal afferents has not been demonstrated in the thalamus or of thalamocortical fibers in the cortex. Progressive reduction in size of cells undergoing transneuronal atrophy and the vacating of synaptic sites on them by withdrawing axons are unlikely to be 


\begin{tabular}{|c|c|c|c|c|c|c|c|}
\hline \multirow[b]{2}{*}{ Case } & \multirow[b]{2}{*}{ Survival time (years) } & \multicolumn{2}{|l|}{$\mathrm{CN}$} & \multicolumn{2}{|l|}{$\mathrm{ECN}$} & \multicolumn{2}{|l|}{ GN } \\
\hline & & Intact & Deafferented & Intact & Deafferented & Intact & Deafferented \\
\hline 1 & 12.8 & 6960 & 6200 & 9780 & 8900 & 280 & 5610 \\
\hline 2 & 13.7 & 4110 & 3640 & 7506 & 6427 & 2825 & 2989 \\
\hline 3 & 13.7 & 4405 & 3740 & 9965 & 8872 & 3106 & 2964 \\
\hline 4 & 14.3 & 7032 & 6259 & 9500 & 8500 & 3890 & 3560 \\
\hline 5 & 15.1 & 4590 & 3745 & 11,000 & 9200 & 3540 & 3410 \\
\hline 6 & 15.1 & 5245 & 3742 & 8850 & 7887 & 4120 & 4159 \\
\hline 7 & 21.2 & 5032 & 2786 & 9287 & 6667 & 3750 & 3623 \\
\hline Mean & & 5339 & 4302 & 9412 & 8064 & 3786 & 3759 \\
\hline SD & & 1193 & 1360 & 1074 & 1117 & 796 & 911 \\
\hline
\end{tabular}

\begin{tabular}{|c|c|c|c|c|c|c|c|}
\hline \multirow[b]{2}{*}{ Case } & \multirow[b]{2}{*}{ Survival time (years) } & \multicolumn{2}{|l|}{$\mathrm{CN}$} & \multicolumn{2}{|l|}{$\mathrm{ECN}$} & \multicolumn{2}{|l|}{ GN } \\
\hline & & Intact & Deafferented & Intact & Deafferented & Intact & Deafferentec \\
\hline 1 & 12.8 & $23 \times 10^{3}$ & $38 \times 10^{3}$ & $16 \times 10^{3}$ & $23 \times 10^{3}$ & $13 \times 10^{3}$ & $14 \times 10^{3}$ \\
\hline 2 & 13.7 & $17 \times 10^{3}$ & $31 \times 10^{3}$ & $16 \times 10^{3}$ & $25 \times 10^{3}$ & $14 \times 10^{3}$ & $14 \times 10^{3}$ \\
\hline 3 & 13.7 & $21 \times 10^{3}$ & $37 \times 10^{3}$ & $15 \times 10^{3}$ & $25 \times 10^{3}$ & $17 \times 10^{3}$ & $16 \times 10^{3}$ \\
\hline 4 & 14.3 & $21 \times 10^{3}$ & $37 \times 10^{3}$ & $19 \times 10^{3}$ & $29 \times 10^{3}$ & $13 \times 10^{3}$ & $13 \times 10^{3}$ \\
\hline 5 & 15.1 & $19 \times 10^{3}$ & $34 \times 10^{3}$ & $10 \times 10^{3}$ & $16 \times 10^{3}$ & $13 \times 10^{3}$ & $13 \times 10^{3}$ \\
\hline 6 & 15.1 & $17 \times 10^{3}$ & $33 \times 10^{3}$ & $9 \times 10^{3}$ & $21 \times 10^{3}$ & $10 \times 10^{3}$ & $10 \times 10^{3}$ \\
\hline 7 & 21.2 & $17 \times 10^{3}$ & $30 \times 10^{3}$ & $9 \times 10^{3}$ & $25 \times 10^{3}$ & $17 \times 10^{3}$ & $17 \times 10^{3}$ \\
\hline Mean & & $19 \times 10^{3}$ & $34 \times 10^{3}$ & $14 \times 10^{3}$ & $24 \times 10^{3}$ & $14 \times 10^{3}$ & $14 \times 10^{3}$ \\
\hline SD & & $2 \times 10^{3}$ & $3 \times 10^{3}$ & $3 \times 10^{3}$ & $4 \times 10^{3}$ & $2 \times 10^{3}$ & $2 \times 10^{3}$ \\
\hline
\end{tabular}

\begin{tabular}{|c|c|c|c|c|c|c|c|}
\hline \multirow[b]{2}{*}{ Case } & \multirow[b]{2}{*}{ Survival time (years) } & \multicolumn{2}{|l|}{ Neuron $n$} & \multicolumn{2}{|c|}{ Neuron volume $\left(\mu \mathrm{m}^{3}\right)$} & \multicolumn{2}{|c|}{ Neuron density $\left(n / \mathrm{mm}^{3}\right)$} \\
\hline & & Intact & Deafferented & Intact & Deafferented & Intact & Deafferented \\
\hline 1 & 12.8 & $159,987.85$ & $136,995.96$ & 4,700 & 3,950 & $64 \times 10^{3}$ & $81 \times 10^{3}$ \\
\hline 2 & 13.7 & $164,962.50$ & $138,924.38$ & 4,500 & 4,000 & $62 \times 10^{3}$ & $78 \times 10^{3}$ \\
\hline 7 & 21.2 & $178,224.95$ & $141,675.91$ & 6,350 & 4,970 & $62 \times 10^{3}$ & $79 \times 10^{3}$ \\
\hline Mean & & $167,725.10$ & $139,198.75$ & 5,183 & 4,306 & $63 \times 10^{3}$ & $79 \times 10^{3}$ \\
\hline $\mathrm{SD}$ & & $6,997.28$ & $1,515.61$ & 1,015 & 575 & $4 \times 10^{3}$ & $8 \times 10^{3}$ \\
\hline
\end{tabular}

passive processes and may be accompanied by induction and release of trophic factors that promote sprouting (Connor and Dragunow, 1998; McAllister et al., 1999). Activity-dependent changes in gene expression for other molecules occurred in VPL of the monkeys of the present series, including upregulation of calbindin and downregulation of $\mathrm{GABA}_{\mathrm{A}}$ receptors (Rausell et al., 1992), but trophic factor regulation has not yet been investigated.

We have no evidence, yet, that the somatosensory cortex of long-term-deafferented monkeys is affected by tertiary transneuronal atrophy. In the present monkeys, 12-13 years after lesion, the cortical representation of the lower part of the face was displaced 10-14 mm toward that of the lower trunk at the expense of the silenced upper limb-upper trunk representation. Transneuronal shrinkage of the upper limb-upper trunk representation of a magnitude similar to that occurring in the brainstem and thalamus could influence this displacement for mechanical reasons. More importantly, the atrophy of cortical cells after with- drawal of axons of atrophying thalamic cells would set in motion the same train of events proposed to effect reorganization in the brainstem and thalamus.

The somatosensory cortex is unlikely to be protected from tertiary transneuronal atrophy after extensive rhizotomies. Campbell (1905) described shrinkage of layers and patchy disorganization of area $3 \mathrm{~b}$ in brains from long-standing cases of tabes dorsalis in which death of dorsal root ganglion cells results in degeneration of the spinal dorsal columns. Similarly, longstanding optic atrophy or loss of an eye, with transneuronal atrophy of the lateral geniculate nucleus, is associated with reduced areal extent and thinning of the visual cortex (Bolton, 1900).

Removal of sensory input by section of the dorsal roots or spinal dorsal columns is different from section of peripheral nerves, either directly or by amputation of a limb, although both lead to cortical reorganization (Jones, 2000). After nerve section, dorsal root ganglion cells usually do not die in large numbers; 


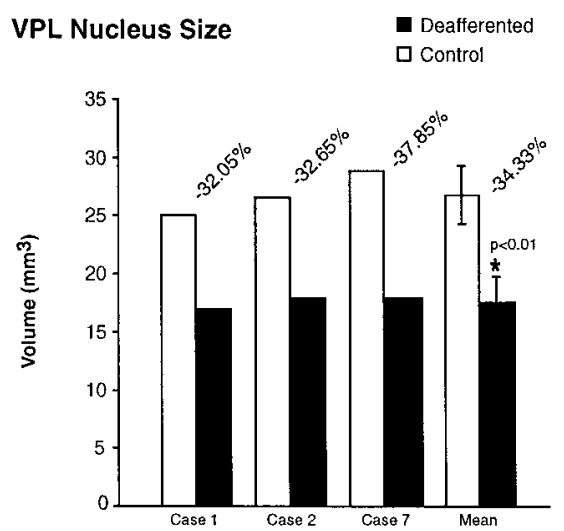

VPL Neuron Number

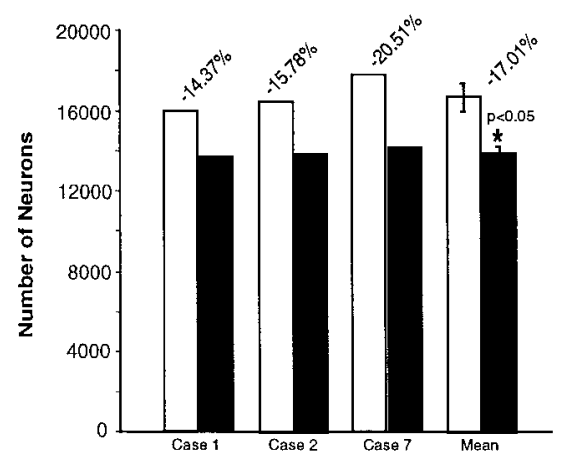

VPL Neuron Size

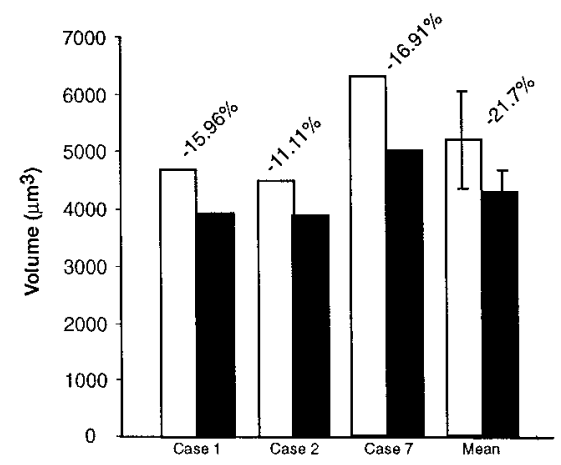

VPL Neuronal Packing Density

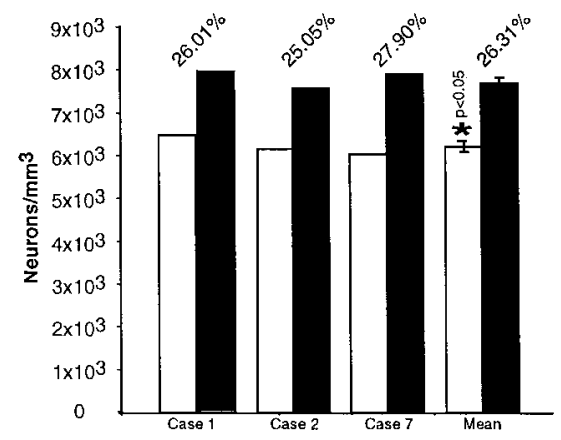

Figure 11. Histograms showing, from top to bottom, the reduction in size of the VPL thalamic nucleus of the affected side in comparison with that of the opposite side, with modest reduction in the number of neurons, cell shrinkage, and the increase in cell density in three of the seven animals subjected to unilateral rhizotomies, arranged in order of shortest (Case 1) to longest (Case 7) survival time. their peripheral axons are capable of regeneration, and their central axons remain intact (Sunderland, 1978; Risling et al., 1983; Devor et al., 1985; Arvidsson et al., 1986; Himes and Tessler, 1989; Lekan et al., 1997). In adult rats, peripheral nerve section with modest ganglion cell loss and neurotoxic destruction of large numbers of ganglion cells have identical effects on shortand medium-term reorganization of somatosensory cortex (Wall et al., 1988; Cusick et al., 1990). Cutting all nerves to a limb is accompanied by considerable ganglion cell loss, and in cats under these circumstances, transneuronal atrophy commences in the cuneate nucleus within 4-5 weeks and becomes marked after 20-36 weeks but without cell loss (Avendaño and Dykes, 1996). Hence, the degree to which amputation or peripheral nerve section leads to primary and secondary transneuronal atrophy will likely depend on the degree to which they cause cell loss in the ganglia. Preservation of small numbers of primary afferent or thalamocortical fibers after dorsal column or thalamic lesions is sufficient to preserve a representation in the cortex (Jain et al., 1997; Jones et al., 1997), so the extent to which longer-term central effects of peripheral deafferentation resemble those of central deafferentation may depend on the extent to which dorsal root ganglion cells that survive peripheral nerve section can support a central representation.

The present observations indicate that the changes occurring in the brainstem and thalamus as the result of central deafferentation are not static and continue over a protracted period after a lesion. They are of a nature that is likely to induce considerable reorganization of these subcortical structures, which will in turn be projected on the sensory cortex with important and probably continuing implications for the reorganization of the cortex itself.

\section{REFERENCES}

Antonini A, Stryker MP (1993) Rapid remodeling of axonal arbors in the visual cortex. Science 260:1819-1821.

Antonini A, Gillespie DC, Crair MC, Stryker MP (1998) Morphology of single geniculocortical afferents and functional recovery of the visual cortex after reverse monocular deprivation in the kitten. J Neurosci 18:9896-9909.

Antonini A, Fagiolini M, Stryker MP (1999) Anatomical correlates of functional plasticity in mouse visual cortex. J Neurosci 19:4388-4406.

Arvidsson J, Ygge J, Grant G (1986) Cell loss in lumbar dorsal root ganglia and transganglionic degeneration after sciatic nerve resection in the rat. Brain Res 373:15-21.

Avendaño C, Dykes RW (1996) Quantitative analysis of anatomical changes in the cuneate nucleus following forelimb denervation: a stereological morphometric study in adult cats. J Comp Neurol 370:491-500.

Bolton JS (1900) The exact localisation of the visual area of the human cerebral cortex. Philos Trans R Soc Lond B Biol Sci 193:165-222.

Burton H, Fabri M (1995) Ipsilateral intracortical connections of physiologically defined cutaneous representations in areas $3 \mathrm{~b}$ and 1 of macaque monkeys: projections in the vicinity of the central sulcus. J Comp Neurol 355:508-538.

Campbell AW (1905) Histological studies on the localization of cortical function. Cambridge, UK: Cambridge UP.

Cook WH, Walker JH, Barr ML (1951) A cytological study of transneuronal atrophy in the cat and rabbit. J Comp Neurol 94:267-291.

Connor B, Dragunow M (1998) The role of neuronal growth factors in neurodegenerative diseases of the human brain. Brain Res Rev 27:1-39.

Cusick CG, Wall JT, Whiting JH, Wiley RG (1990) Temporal progression of cortical reorganization following nerve injury. Brain Res 537:355-358.

Darian-Smith C, Gilbert CD (1994) Axonal sprouting accompanies functional reorganization in adult cat striate cortex. Nature 368:737-740.

De Felipe J, Conley M, Jones EG (1986) Long-range focal collateralization of axons arising from corticocortical cells in monkey sensory-motor cortex. J Neurosci 6:3749-3766. 
Devor M, Govrin-Lippmann R, Frank I, Raber P (1985) Proliferation of primary sensory neurons in adult rat dorsal root ganglion and the kinetics of retrograde cell loss after sciatic nerve section. Somatosens Res 3:139-167.

Dostrovsky JO, Millar J, Wall PD (1976) The immediate shift of afferent drive of dorsal column nucleus cells following deafferentation: a comparison of acute and chronic deafferentation in gracile nucleus and spinal cord. Exp Neurol 52:480-495.

Elbert H, Sterr A, Flor H, Rockstroh B, Knecht S, Pantev C, Weinbruch C, Taub E (1997) Input-increase and input-decrease types of cortical reorganization after upper extremity amputation in humans. Exp Brain Res 117:161-164.

Flor H, Elbert H, Knecht S, Weinbruch C, Pantev C, Birnbaumer N, Larbig W, Taub E (1995) Phantom limb as a correlate of cortical reorganization following arm amputation. Nature 357:482-484.

Florence SL, Kaas JH (1995) Large-scale reorganization at multiple levels of the somatosensory pathway follows therapeutic amputation of the hand in monkeys. J Neurosci 15:8083-8095.

Florence SL, Wall JT, Kaas JH (1989) Somatotopic organization of inputs from the hand to the spinal gray and cuneate nucleus of monkeys with observations on the cuneate nucleus of humans. J Comp Neurol 286:48-70.

Florence SL, Wall JT, Kaas JH (1991) Central projections from the skin of the hand in squirrel monkeys. J Comp Neurol 311:563-578.

Florence SL, Garraghty PE, Wall JT, Kaas JH (1994) Sensory afferent projections and area $3 \mathrm{~b}$ somatotopy following median nerve cut and repair in macaque monkeys. Cereb Cortex 4:391-407.

Florence SL, Taub HB, Kaas JH (1998) Large-scale sprouting of cortical connections after peripheral injury in adult macaque monkeys. Science 282:1117-1121.

Garraghty PE, Kaas JH (1991) Functional reorganization in adult monkey thalamus after peripheral nerve injury. NeuroReport 2:747-750.

Goldby F (1957) A note on transneuronal atrophy in the human lateral geniculate body. J Neurol Neurosurg Psychiatry 20:202-207.

Gundersen HJG, Bagger P, Bendtsen TF, Evans SM, Korbo L, Marcussen N, Moller A, Nielsen K, Nyengaard JR, Pakkenberg B, Sorensen FB, Vesterby A, West MJ (1988) The new stereological tools: disector, fractionator, nucleator and point sampled intercepts and their use in pathological research and diagnosis. APMIS 96:857-881.

Himes BT, Tessler A (1989) Death of some dorsal root ganglion neurons and plasticity of others following sciatic nerve section in adult and neonatal rats. J Comp Neurol 284:215-230.

Jain N, Catania KC, Kaas JH (1997) Deactivation and reactivation of somatosensory cortex after dorsal spinal cord injury. Nature 386:495-498.

Jones EG (2000) Cortical and subcortical contributions to activitydependent plasticity in primate somatosensory cortex. Annu Rev Neurosci, in press.

Jones EG, Pons TP (1998a) Morphological and physiological changes in the somatosensory thalamus of monkeys subjected to upper limb deafferentation for many years. Soc Neurosci Abstr 24:1512.

Jones EG, Pons TP (1998b) Thalamic and brainstem contributions to large-scale plasticity of primate somatosensory cortex. Science 282:1121-1125.

Jones EG, Manger PR, Woods TM (1997) Maintenance of a somatotopic cortical map in the face of diminishing thalamocortical inputs. Proc Natl Acad Sci USA 94:11003-11007.

Kaas JH (1995) The plasticity of sensory representation in adult primates. In: Brain and memory: modulation and mediation (Weinberger NM, McGaugh JL, Lynch G, eds), pp 206-221. New York: Oxford UP.

Kaas JH, Merzenich MM, Killackey HP (1983) The reorganization of somatosensory cortex following peripheral nerve damage in adult and developing mammals. Annu Rev Neurosci 6:325-356.

Kalaska J, Pomeranz B (1982) Chronic peripheral nerve injuries alter the somatotopic organization of the cuneate nucleus in kittens. Brain Res 236:35-47.

Knecht S, Henningsen H, Elbert T, Flor H, Hohling C, Pantev C, Taub E (1996) Reorganization and perceptional changes after amputations. Brain 119:1213-1219.

Kupfer C (1965) The distribution of cell size in the lateral geniculate nucleus of man following transneuronal cell atrophy. J Neuropathol Exp Neurol 24:653-661.

Lekan HA, Chung K, Yoon YW, Chung JM, Coggeshall RE (1997) Loss of dorsal root ganglion cells concomitant with dorsal root axon sprouting following segmental nerve lesions. Neuroscience 81:527-534.
Lenz FA, Kwan HCV, Martin R, Tasker R, Richardson RT, Dostrovsky JO (1994) Characteristics of somatotopic organization and spontaneous neuronal activity in the region of the thalamic principal sensory nucleus in patients with spinal cord transection. J Neurophysiol 72:1570-1587.

Lombard MC, Nashold Jr BS, Albe-Fessard D, Salman N, Sakr C (1979) Deafferentation hypersensitivity in the rat after dorsal rhizotomy: a possible animal model of chronic pain. Pain 6:163-174.

Lowey AD (1973) Transneuronal changes in the gracile nucleus. J Comp Neurol 147:497-510.

Manger PR, Woods TM, Muñoz A, Jones EG (1997) Hand/face border as a limiting boundary in monkey somatosensory cortex. J Neurosci 17:6338-6351.

Matthews MR (1964) Further observations on transneuronal degeneration in the lateral geniculate nucleus of the macaque monkey. J Anat 98:255-263.

Matthews MR, Powell TPS (1962) Some observations on transneuronal cell degeneration in the olfactory bulb of the rabbit. J Anat 96:89-102.

Matthews MR, Cowan WM, Powell TPS (1966) Transneuronal cell degeneration in the lateral geniculate nucleus of the macaque monkey. J Anat 94:145-169.

Mayhew TM (1992) A review of recent advances in stereology for quantifying neural structure. J Neurocytol 21:313-328.

McAllister AK, Katz LC, Lo DC (1999) Neurotrophins and synaptic plasticity. Annu Rev Neurosci 22:295-318.

Merzenich MM, Kaas JH, Wall J, Nelson RJ, Sur M, Felleman D (1983) Topographic reorganization of somatosensory cortical areas $3 \mathrm{~b}$ and 1 in adult monkeys following restricted deafferentation. Neuroscience $8: 33-55$.

Merzenich MM, Nelson RJ, Stryker MP, Cynader MS, Schoppmann A, Zook JM (1984) Somatosensory cortical map changes following digit amputation in adult monkeys. J Comp Neurol 224:591-605.

Millar J, Basbaum AI, Wall PD (1976) Restructuring of the somatotopic map and appearance of abnormal neuronal activity in the gracile nucleus after partial deafferentation. Exp Neurol 50:658-672.

Nakahama H, Nishioka S, Otsuka T (1966) Excitation and inhibition in ventrobasal thalamic neurons before and after cutaneous input deprivation. Prog Brain Res 21:180-196.

Nicolelis MAL, Lin RCS, Woodward DJ, Chapin JK (1993) Induction of immediate spatiotemporal changes in thalamic networks by peripheral block of ascending cutaneous information. Proc Natl Acad Sci USA 90:2212-2216.

Northgrave SA, Rasmusson DD (1996) The immediate effects of peripheral deafferentation on neurons of the cuneate nucleus in raccoon. Somatosens Mot Res 13:103-113.

Panetsos F, Nuñez A, Avendaño C (1997) Electrophysiological effects of temporary deafferentation on two characterized cell types in the nucleus gracilis of the rat. Eur J Neurosci 9:563-572.

Penman J, Smith MC (1950) Degeneration of the primary and secondary sensory neurones after trigeminal injection. J Neurol Neurosurg Psychiatry 13:36-46.

Parker JL, Wood ML, Dostrovsky JO (1998) A focal zone of thalamic plasticity. J Neurosci 18:548-558.

Pettit MJ, Schwark HD (1993) Receptive field reorganization in dorsal column nuclei during temporary denervation. Science 262:2054-2056.

Pollin B, Albe-Fessard D (1979) Organization of somatic thalamus in monkeys with and without section of dorsal spinal tracts. Brain Res 173:431-449.

Pons TP, Garraghty PE, Ommaya AK, Kaas JH, Taub E, Mishkin M (1991) Massive cortical reorganization after sensory deafferentation in adult macaques. Science 252:1857-1860.

Powell TPS (1967) Transneuronal cell degeneration in the olfactory bulb shown by the Golgi method. Nature 215:425-426.

Powell TPS, Erulkar SD (1962) Transneuronal cell degeneration in the auditory relay nuclei of the cat. J Anat 96:249-268.

Rasmusson DD (1996a) Changes in the response properties of neurons in the ventroposterior lateral thalamic nucleus of the raccoon after peripheral deafferentation. J Neurophysiol 75:2441-2450.

Rasmusson DD (1996b) Changes in the organization of the ventroposterior lateral thalamic nucleus after digit removal in adult raccoon. J Comp Neurol 364:92-103.

Rasmusson DD, Northgrave SA (1997) Reorganization of the raccoon CN after peripheral denervation. J Neurophysiol 78:2924-2936.

Rausell E, Jones EG (1991) Chemically distinct compartments of the thalamic VPM nucleus in monkeys relay principal and spinal trigeminal 
pathways to different layers of the somatosensory cortex. J Neurosci 11:226-237.

Rausell E, Jones EG (1995) Extent of intracortical arborization of thalamocortical axons as a determinant of representational plasticity in monkey somatic sensory cortex. J Neurosci 15:4270-4288.

Rausell E, Cusick CG, Taub E, Jones EG (1992) Chronic deafferentation in monkeys differentially affects nociceptive and non-nociceptive pathways distinguished by specific calcium-binding proteins and downregulates $\mathrm{GABA}_{\mathrm{A}}$ receptors at thalamic levels. Proc Natl Acad Sci USA 89:2571-2575.

Rausell E, Bickford L, Manger PR, Woods TM, Jones EG (1998) Extensive divergence and convergence in the thalamocortical projection to monkey somatosensory cortex. J Neurosci 18:4216-4232.

Risling M, Aldskogius H, Hildebrand C, Remahl S (1983) Effects of sciatic nerve resection on L7 spinal roots and dorsal root ganglia in adult cats. Exp Neurol 82:568-580.

Shin HC, Park S, Son J, Sohn JH (1995) Responses from new receptive fields of VPL neurones following deafferentation. NeuroReport 7:33-36.

Sloper J, Headon MP, Powell TP (1987) Effects of enucleation at different ages on the sizes of neurons in the lateral geniculate nucleus of infant and adult monkeys. Brain Res 428:259-265.

Sretevan DW, Shatz CJ (1986) Prenatal development of cat retinogeniculate axon arbors in the absence of binocular interactions. J Neurosci 6:990-1003.

Sunderland S. (1978) Nerve and nerve injuries. New York: Churchill.

Taub E (1980) Somatosensory deafferentation research with monkeys: implications for rehabilitation medicine. In: Behavioral psychology in rehabilitation medicine: clinical applications (Ince LP, ed), pp 371-401. Baltimore: Williams \& Wilkins.
Wall PD, Egger MD (1971) Formation of new connexions in adult rat brains following partial deafferentation. Nature 232:542-545.

Wall JT, Cusick CG, Migani-Wall SA, Wiley RG (1988) Cortical organization after treatment of a peripheral nerve with ricin: an evaluation of the relationship between sensory neuron death and cortical adjustments after nerve injury. J Comp Neurol 277:578-592.

West MJ (1993) New stereological methods for counting neurons. Neurobiol Aging 14:275-285.

Woods TM, Popken GJ, Jones EG (1998) Reduction in volume of the cuneate nucleus in adult monkeys following long-term deafferentation of the upper limb. Soc Neurosci Abstr 24:1512.

Woods TM, Ho C, Jones EG (1999) Transneuronal atrophy in the dorsal column nuclei and thalamus following long-term dorsal rhizotomies in adult monkeys. Soc Neurosci Abstr 25:403.

$\mathrm{Xu} \mathrm{J}$, Wall JT (1996) Cutaneous representations of the hand and other body parts in the cuneate nucleus of a primate, and some relationships to previously described cortical representations. Somatosens Mot Res $13: 187-197$

Xu J, Wall JT (1997) Rapid changes in brainstem maps of adult primates after peripheral injury. Brain Res 774:211-215.

Xu J, Wall JT (1999a) Evidence for brainstem and supra-brainstem contributions to rapid cortical plasticity in adult monkeys. J Neurosci 19:7578-7590.

Xu J, Wall JT (1999b) Normal functional organization of tactile inputs from the hand in the cuneate nucleus and its representation in cortical area 3b. J Comp Neurol 411:369-389.

Zhang SP, Rowe MJ (1997) Quantitative analysis of cuneate neurone responsiveness in the cat in association with reversible, partial deafferentation. J Physiol (Lond) 505:769-783. 